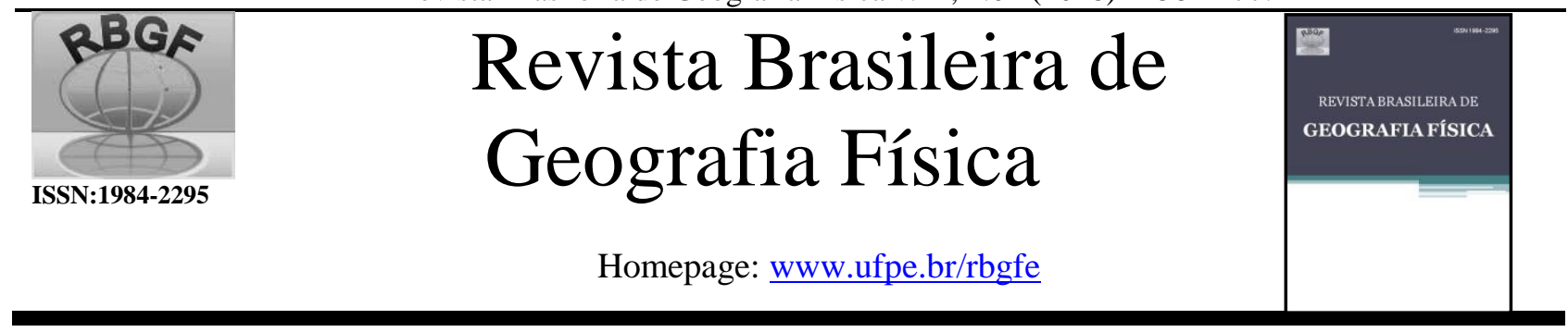

\title{
Dinâmica do uso e cobertura da terra no município de Miranda-MS, Pantanal Sul
}

\author{
Vanessa Aline Wagner Leite ${ }^{1}$, Lidiane Perbelin Rodrigues², Emerson Figueiredo Leite ${ }^{3}$
}

${ }^{1}$ Bacharela em Geografia pela Universidade Federal de Mato Grosso do Sul. Bolsista Capes e Mestranda em Geografia Programa de Pós-graduação em Geografia - Fundação Universidade Federal de Mato Grosso do Sul - UFMS, Rua Oscar Trindade de Barros, 740, Bairro da Serraria - Unidade II, Aquidauana, Mato Grosso do Sul, Brasil. CEP: 79200-000. Fone (067) 3241.0450. Autor correspondente (vanessawleite@gmail.com).

${ }^{2}$ Licenciada em Geografia pela Universidade Federal de Mato Grosso do Sul. Bolsista Capes e Mestranda em Geografia - Programa de Pós-graduação em Geografia - Fundação Universidade Federal de Mato Grosso do Sul - UFMS, Rua Oscar Trindade de Barros, 740, Bairro da Serraria - Unidade II, Aquidauana, Mato Grosso do Sul, Brasil. CEP: 79200000. Fone (067) 3241.0450. (lidiane_perbelin@ hotmail.com).

${ }^{3}$ Prof. Dr Adjunto II, Fundação Universidade Federal de Mato Grosso do Sul - UFMS, Rua Oscar Trindade de Barros, 740, Bairro da Serraria - Unidade II, Aquidauana, Mato Grosso do Sul, Brasil. CEP: 79200-000. Fone (067) 3241.0450. (emerson.leite@ufms.br).

Artigo recebido em 09/11/2017 e aceito em 24/07/2018

\section{R E S U M O}

O município de Miranda ocupa uma extensão territorial de 5.478,82km localizados entre os paralelos $20^{\circ} 29^{\prime}$ e $19^{\circ} 39^{\prime}$ Sul, e meridianos $57^{\circ} 01^{\prime}$ e $56^{\circ} 11^{\prime}$ Oeste. Este munícipio foi escolhido como objeto de estudo desta pesquisa por contemplar áreas dos domínios Cerrado e Pantanal, além de remanescentes da Mata Atlântica, estando situado no contexto da bacia do Alto Paraguai. O objetivo deste trabalho foi analisar a dinâmica de uso e cobertura da terra do município Miranda-MS nos anos de 2006, 2011 e 2017 usando o software Spring/Inpe. Durante a pesquisa foram utilizadas imagens dos satélites Landsat 5-TM e 8-OLI, cena 226/74, que foram processadas no Spring 4.3.3. Para atenuar as diferenças existentes entre as imagens de diferentes sensores imageadores foi realizada a correção atmosférica das imagens e para ressaltar os remanescentes florestais do Pantanal, Cerrado e Mata Atlântica foi aplicado o Normalized Difference Vegetation Índex (NDVI). Para classificação das imagens foi utilizado o Método híbrido de Moreira (2012) e o classificador empregado foi o Isoseg. As classes adotadas no mapeamento foram adaptadas do IBGE (2013): Cicatriz de Queimada, Remanescentes Florestais, Campo/Pasto, Corpos D’água, Área Urbana - Miranda, Agricultura Irrigada. Os resultados obtidos permitiram aferir a grande influência hidroclimática e do relevo nas mudanças no uso e cobertura da terra observadas, uma vez que anos de seca são favoráveis ao avanço da antropização de áreas naturais e sua consequente fragmentação.

Palavras-chave: Uso e Cobertura da Terra; Sensoriamento Remoto; Cerrado; Pantanal.

\section{Land use and land cover dynamics in the municipality of Miranda, Mato Grosso do Sul State,}

\section{South Pantanal, Brazil}

\begin{abstract}
A B S T R A C T
The municipality of Miranda occupies a land area of 5.478,82km located between parallels $20^{\circ} 29^{\prime}$ and $19^{\circ} 39^{\prime}$ South and meridians $57^{\circ} 01^{\prime}$ and $56^{\circ} 11^{\prime}$ 'West. This location has been chosen because it includes areas of both Brazilian Cerrado and Pantanal biomes besides residual fragments of Mata Atlântica, situated in the context of the Alto Paraguai Basin. This paper aimed to analyse the dynamics of land use and land cover within the municipality of Miranda in the years of 2006, 2011 and 2017using Spring/Inpe software. It was used Landsat 5-TM e 8-OLI, scene 226/74 satellite images processed on Spring 4.3.3. In order to smooth disparities between images from distinct imager sensors it was used atmospheric correction and to emphasize forest remnants of Pantanal, Cerrado and Mata Atlântica it was applied Normalized Difference Vegetation Index(NDVI).To classify the images, it was used the hybrid method of Moreira (2012) with Isoseg
\end{abstract}

Leite, V. A. W. Rodrigues, L. P., Leite, E. F. 
Revista Brasileira de Geografia Física v.11, n.04 (2018) 1458-1477.

classifier. The classes were adapted from IBGE (2013): burned areas, forest remnants, grass field/pasture, water bodies, Miranda's urban area, irrigated agriculture. The results have allowed to measure hydroclimatic and relief influence on land use and land cover changes since dry years are positive to anthropization progress in natural areas as well as their resulting fragmentation.

Key words: Land use and land cover; Brazilian Cerrado; Pantanal. Remote Sensing;

\section{Introdução}

O presente trabalho tem como objetivo analisar a dinâmica do Uso e Cobertura da Terra no Município de Miranda (MS) nos anos de 2006, 2011 e 2017, através do emprego do software Spring/Inpe (Câmara et al.., 1996). O Município de Miranda foi escolhido como objeto de estudo por contemplar áreas de Cerrado e Pantanal, além de abranger áreas com presença de remanescentes florestais de Mata Atlântica, razão pela qual, o município pode ser caracterizado como uma região de ecótonos. Dessa forma, entende-se que a presença dos três biomas torna Miranda um município de grande biodiversidade e dinâmica socioambiental peculiar, uma vez que em cada domínio supracitado são observadas características geomorfológicas, pedológicas e geológicas diferenciadas, sendo afetados pelo clima e pela ocupação antrópica também de maneira diferente.

Há, por exemplo, diferenças entre as consequências do desmatamento ocorrido na Planície e no Planalto. Ao analisar áreas no Pantanal, Sakamoto et al. (2012) comprovaram que o desmatamento das chamadas cordilheiras, que são áreas elevadas na planície (1-3m), pode afetar a dinâmica ambiental através de alterações na morfologia do solo, no nível freático e diminuir a umidade dessas áreas desmatadas.

Enquanto, já o desmatamento ocorrido no planalto apresenta como principal implicação o aceleramento dos processos erosivos, que além da perda de qualidade ambiental nas áreas planálticas tem resultados também na planície, uma vez que gera assoreamento dos rios, ampliação das áreas de inundação permanente e perda de habitats no Pantanal (Silva et al., 2010).

Bazzo et al. (2012) apontam que as principais agressões ambientais ao Pantanal afetam os rios e o solo, e são decorrentes da expansão da fronteira agrícola.

Em estudo experimental Gazola e Gonçalves (2017) demonstraram o recuo das margens do Rio Miranda, na região do Passo do Lontra (município de Corumbá, região do Pantanal) o que evidencia a influência da cobertura vegetal ciliar para este ambiente fluvial, cuja presença poderia mitigar a ação dos processos erosivos, assim como a conservação da vegetação na bacia hidrográfica do Rio Miranda, dessa forma, os autores indicaram a necessidade de análise da expansão e dos impactos do desmatamento e inserção de forrageiras exóticas na região do pantanal e áreas de influência, como o planalto adjacente.

Segundo Hogan et al.(2010), a partir da década de 1970, a expansão da fronteira agrícola se intensificou, dessa forma, Alves et al. (2012) apontam que no Estado de Mato Grosso do Sul houve massificação da ocupação antrópica trazendo impactos para a Bacia do Alto Paraguai.

Essa ocupação gerou implicações também para a dinâmica das sub-bacias hidrográficas da Bacia do Alto Paraguai, conforme caracterizado por Ferraz (2006), que analisou o uso e cobertura da terra na bacia hidrográfica do Rio Miranda entre 1973 e 2006 e Rodrigues e Leite (2017) que estudaram o uso e cobertura da terra na Bacia do Rio Aquidauana (maior afluente do rio Miranda) entre 1973 e 2015, ambos confirmando o avanço das áreas antropizadas sobre as áreas naturais, em que áreas de vegetação natural foram desmatadas para inserção de atividades agropecuárias.

Essa dinâmica socioambiental é marcante característica da região centro-oeste do estado de Mato Grosso do Sul, contudo, ela deve ser analisada com cautela, uma vez que a Bacia do Alto Paraguai apresenta vulnerabilidade ambiental acentuada devido à presença do Pantanal.

O Pantanal tem como uma de suas características a presença de drenagem distributária e rios mutantes, sendo que tal característica deve ser considera pelas políticas públicas que visem o desenvolvimento sustentável, assim como a importância do conhecimento das dinâmicas ambientais para a sua ocupação racional e preservação (Assine, 2016).

Todavia, segundo Harris (2005) o desmatamento na Planície se intensificou nas últimas décadas, tornando-se uma ameaça ainda maior que o desmatamento no Planalto circundante, sendo que cerca de $40 \%$ da vegetação florestal e savânicas do Pantanal foram removidas para dar lugar à pastagem, muitas vezes de gramíneas exóticas, além da ameaça das queimadas, pratica de manejo utilizada para renovação de pastagens e controle de pragas.

Nesse contexto, iniciativas como as do Projeto de "Monitoramento das alterações da cobertura vegetal e uso do solo na Bacia do Alto Paraguai - Porção Brasileira", desenvolvido pela Embrapa, Instituto SOS Pantanal e o WWF-Brasil, 
Revista Brasileira de Geografia Física v.11, n.04 (2018) 1458-1477.

que vem acompanhando as mudanças na BAP desde o ano de 2002, tornam-se cada vez mais importantes ao fornecer um panorama do Uso e Cobertura no Planalto e Planície.

Neste estudo constatou-se que nas regiões planálticas da BAP, no ano de 2014, restavam apenas $39,5 \%$ de áreas naturais, enquanto no Pantanal restavam $85,1 \%$ de áreas naturais, sendo que entre os anos de 2012 e 2014, 99\% das áreas naturais convertidas em áreas antropizadas da BAP tiveram como objetivo a implantação de pastagens, além de que o dado mais impactante foi relativo à taxa de conversão de áreas naturais em áreas antropizadas, pois foi a primeira vez que o levantamento constatou que a taxa de alteração no Pantanal foi $0,02 \%$ maior que no Planalto, contrapondo-se aos períodos de 2002 a 2008, e 2010 a 2012 em que os índices de conversão foram maiores no planalto, sendo no primeiro período $1,6 \%$ e no segundo período 0,06 maior no Planalto (WWF-Brasil,2009; 2013; 2015).

Avaliar as transformações que ocorrem no espaço e os respectivos impactos ambientais através do uso de produtos de sensoriamento remoto e técnicas de geoprocessamento ainda é o meio mais econômico e eficaz de monitorar as alterações do meio (Matiello et al., 2017).

Nesse sentido compreender as mudanças e alterações no uso da terra ao longo dos anos tornase essencial para alcançar o equilíbrio dos sistemas naturais e a utilização de maneira sustentável dos seus recursos (Rosa et al., 2017).

Dessa forma, a análise do uso e cobertura da terra na BAP em escala compatível com os municípios que dela fazem parte torna-se importante, em especial se tratando de Miranda, pois conforme ressaltado por Silva et al. (2010) as diferenças entre os limites do que é Planície ou Pantanal, e o que é Planalto ou Cerrado leva a muitas incorreções nos trabalhos realizados nesta região. Dessa forma, a escala de trabalho tem grande influência na análise e no caso do município de Miranda, os aspectos topográficos e fitofisionômicos também.

Nessas regiões de ecótonos entre os biomas é importante levar em consideração também as características do relevo, uma vez que a topografia da superfície tem grande relevância nos tipos de cobertura vegetal e também nos tipos de usos a serem adotados.

De acordo com Landau e Guimarães (2011) o mapeamento das variáveis do relevo como a declividade atua como uma ferramenta facilitadora para a identificação de áreas mais propícias para a agricultura no que tange determinar regiões que necessitem de mecanização para prevenção e controle de processos erosivos entre, além de permitir que se indiquem áreas destinadas à conservação ou recuperação do solo e da biodiversidade.

Esses autores também sugerem que os usos dos MNTs para a extração dessas variáveis sejam de suma importância para o "planejamento do uso do espaço agrícola, gestão ambiental, manejo de bacias hidrográficas, zoneamentos ecológicos, programas de conservação de florestas e de solo, entre outros" (Landau e Guimarães, 2011, p. 4003).

Dentre os dados morfométricos, a Declividade $(\mathrm{S})$, caracterizada como "o ângulo de inclinação da superfície local em relação ao plano horizontal" (Valeriano, 2008, p. 85-86), apresenta grande destaque. As classes de declividade podem ser medidas em graus ou porcentagens e geralmente revelam características importantes do terreno.

Diante do exposto, entende-se que analisar a dinâmica de uso e cobertura da terra de Miranda assim como correlacionar com a declividade do terreno possa auxiliar no Planejamento Ambiental e Territorial do município, de modo a subsidiar o desenvolvimento sustentável municipal.

\section{Referencial Teórico}

Geografia e Geotecnologias- O ser humano vem provocando alterações adversas na fisionomia das paisagens ao reproduzir seu modo de vida, produção e desenvolvimento. Tais ações antrópicas vêm gerando impactos ambientais em nível local, regional e global, aumento da pressão sobre os recursos naturais e sobre elementos do meio físico, causando o rompimento de dinâmicas sistêmicas, ampliando riscos de degradação e vulnerabilidades ambientais (Melo e Santos, 2010).

É a relação estabelecida entre a sociedade e a natureza que determina a intensidade e os diferentes problemas ambientais que possam ocorrer, ou seja, determina a qualidade ambiental (Verona et al., 2003).

Santos (1996) afirma que a principal forma de relação entre homem e meio é mediada pela técnica, que são os recursos instrumentais e sociais com os quais o homem realiza sua vida, produz e ao mesmo tempo, cria o espaço. Bernardes (2010) salienta a importância de se apreender o significado social e político da implantação da técnica em sua dimensão espacial, pois estas modificam a relação com o espaço, e geram implicações de ordem social e territorial.

Ademais, salienta-se a dimensão socioespacial dos problemas de ordem ambiental. Ao interferir na qualidade do ambiente, as ações antrópicas geram repercussões por toda a 


\section{Revista Brasileira de Geografia Física v.11, n.04 (2018) 1458-1477.}

sociedade, pois a perda de qualidade ambiental interfere na vida humana, da mesma forma que o ser humano interfere nos processos ambientais, gerando um processo autocíclico de retroalimentação com consequências na organização espacial.

Loureiro (2011) aponta ainda que a forma como o ambiente se apresenta espelha a qualidade ambiental, e esta é um fator preponderante na manutenção do bem-estar em uma sociedade, sendo que sua deterioração está intimamente relacionada à queda da qualidade de vida da população.

Ao refletir sobre esses questionamentos, observa-se que a produção do espaço geográfico no século XXI apresenta-se perpassada de contradições. As diversas crises econômicas, políticas e administrativas vivenciadas em todo o planeta e no Brasil, associadas a vulnerabilidades socioeconômicas e ambientais inerentes a organização social imposta pelo Capitalismo levantam questionamento quanto às consequências dessa conjuntura para a qualidade ambiental das áreas urbanas e rurais.

A partir dessa leitura de mundo, a Geografia possui a responsabilidade e os métodos para analisar esses processos e suas repercussões no espaço geográfico através de análises espaciais que englobem aspectos socioeconômicos e ambientais.

Diante do exposto, considera-se que a análise do espaço geográfico ganha cada vez mais importância e utilizar as tecnologias atualmente disponíveis torna-se imperativo diante da necessidade de realizar o Planejamento Territorial e Ambiental.

Nesse contexto, as chamadas Geotecnologias, definidas por Fitz (2008) como novas tecnologias ligadas às geociências e suas áreas afins ganham cada vez mais importância uma vez que possibilitam imensa gama de utilização podendo ser utilizadas "pelos órgãos governamentais na identificação das potencialidades e fragilidades de cada região" (Rosa et al., 2017, p. 6890).

Zaidan (2017, p. 198) aponta que o Geoprocessamento é a mais destacada entre as geotecnologias, especialmente devido aos Sistemas de Informação Geográfica (SIG), podendo ser definido como um "conjunto de técnicas e métodos teóricos e computacionais relacionados com a coleta, entrada, armazenamento, tratamento e processamento de dados, a fim de gerar novos dados e ou informações espaciais ou georreferenciadas".

As geotecnologias permitem a análise e representação do espaço geográfico com aplicação de metodologias consistentes e de modo a interagirem harmonicamente com o peopleware qualificado para a utilização das ferramentas digitais atuais e com o público em geral, uma vez que essas informações sejam distribuídas através da rede mundial de computadores, originando-se a Ciência da Geoinformação.

Análise e Representação do Espaço Geográfico A concepção de Espaço Geográfico a luz da ciência da Geoinformação pode ser obtida em Câmara e Medeiros (1998a, p. 71): "coleção de localizações na superfície da Terra, sobre a qual ocorrem os fenômenos geográficos", dessa forma o emprego de Geotecnologias em pesquisas geográficas deve ser enxergado como um avanço, mas também com cautela, uma vez que estas caracterizam o meio, não o fim das pesquisas desta ciência.

Silva e Veiga (2007) salientam que essas novas tecnologias garantem maior acessibilidade, precisão e velocidade de obtenção e processamento dos dados geográficos, proporcionando conhecer melhor o espaço e a sociedade que o produz, espacializando a relação entre eles e subsidiando a tomada de decisões seja no âmbito social, econômico ou ambiental.

Tais análises são possíveis através de dados oriundos das mais diferentes fontes, dos quais destacam-se os dados advindos do Sensoriamento Remoto, uma vez que estes constituem-se de informações numéricas e imagens orbitais que são adquiridas através de técnicas de coleta de dados por plataformas dos mais diversos níveis, como o orbital, dos quais são provenientes os dados utilizados neste trabalho.

Nessas imagens digitais, conforme Florenzano (2011), cada pixel representa um valor que corresponde à intensidade da energia refletida ou emitida pelos objetos imageados, gerando dessa forma imagens no formato matricial, que, segundo Moreira (2012), devido às suas características podem passar por processos de tratamento que melhorem sua qualidade ou gerem novas imagens e produtos.

Novo (2010) salienta que a grande vantagem das imagens digitais, em comparação com as imagens analógicas, é o fato de que as estas podem ser processadas utilizando-se de técnicas que possibilitem o realce para uma melhor discriminação dos alvos de interesse e extração de informações específicas de cada um dos pixels que a compõem.

Entretanto, Florenzano (2011, p. 71) afirma que "É fundamental compreender o tipo de transformação aplicada aos dados de sensoriamento remoto, para evitar a perda de informação e erros na sua análise e interpretação". Dessa forma, é 
Revista Brasileira de Geografia Física v.11, n.04 (2018) 1458-1477.

necessário conhecimento técnico-científico inerente ao Geoprocessamento, Sensoriamento Remoto, Sistemas de Informações Geográficas e Cartografia, que possibilitem a utilização de ferramentas de análise e representação espacial na elaboração de trabalhos com qualidade cartográfica e geográfica.

A análise geoespacial deve-se pautar pelo rigor científico e técnico, e na qualidade das suas fontes de dados. Rocha (2000) condiciona a efetividade do Geoprocessamento à disponibilidade de dados com qualidade de utilização em seus bancos de dados espaciais, sendo que sem esta condição básica o geoprocessamento não alcançará seus objetivos. A qualidade espacial dos dados e o refinamento o qual se exigirá dependendo da pesquisa desenvolvida faz do SIG e do software de SIG elementos essenciais na análise.

Um SIG tem como grande diferencial em relação a outros sistemas de informação é a sua capacidade de realizar análises de dados espaciais (Câmara e Medeiros, 1998b) e apresentar uma visualização do padrão espacial do fenômeno geográfico (Câmara et al., 2004). Os SIGs permitem uma manipulação de dados mais eficiente em relação às interpretações analógicas, em especial no que tange ao Processamento Digital de Imagens.

Processamento Digital de Imagens -Segundo Moreira (2012, p. 218) o Processamento Digital de Imagens é a "manipulação de uma imagem por computador de modo que a entrada e a saída do processo sejam imagens". Dessa forma, realiza-se o Processamento no intuito de preparar a imagem para a utilização do analista.

Essa manipulação das imagens é o principal diferencial entre a Cartografia Automatizada e o Processamento Digital de Imagem realizado nos softwares de Sistemas de informação Geográfica, uma vez que a Cartografia Automatizada possibilita captar, organizar e desenhar mapas, sendo dessa forma uma versão digital das técnicas manuais, enquanto que os SIGs e o PDI representam uma modificação profunda nos procedimentos e técnicas de processar imagens e dados digitais, dentre os quais inclui-se a manipulação numérica de imagens, assim como obtenção, armazenamento e manipulação, análise e apresentação de dados georreferenciados (Rosa e Brito, 1996).

Ponzoni e Shimabukuro (2007) salientam as diferenças entre a interpretação visual e o processamento digital de imagens, para os autores a interpretação visual é suficiente para análises qualitativas, contudo, análises mais quantitativas são beneficiadas pelo processamento digital de imagens, uma vez que a visão humana é capaz de detectar informações oriundas de apenas três bandas espectrais e de grupos de pixels, enquanto o processamento digital é capaz de trabalhar com diversas bandas e analisando cada pixel da imagem.

O processamento digital de imagens é um importante aliado para o "reconhecimento de mudanças nas atividades agrícolas e pecuárias, principal fonte de renda da população rural, bem como mudanças nas áreas florestais nativas amparadas pela legislação ambiental" (Facco et al., 2017, p. 6847).

Essas metodologias de aplicação e tratamento de dados devem levar em consideração as características inerentes às imagens utilizadas e dos objetivos da pesquisa.

\section{Retificação Radiométrica ou Correção}

Atmosférica - Nas análises da dinâmica de uso e cobertura da terra que utilizam imagens de diferentes datas e/ou sensores, há algumas rotinas metodológicas que auxiliam na preparação das imagens como a Retificação Atmosférica, ou Correção Atmosférica, como também é conhecida. Nesse procedimento entende-se que o alvo de interesse é o objeto imageado e este sinal ao sofrer interferência atmosférica é considerado um ruído, para corrigi-lo deve-se utilizar modelos matemáticos que considerem os parâmetros da atmosfera e dos sensores imageadores (Antunes et al., 2003).

Esta interferência "afeta a radiância refletida pela superfície que é captada pelo sensor, por causa dos fenômenos de espalhamento, absorção e refração da energia eletromagnética" (Nascimento et al., 2017, p. 02).

Dentre os modelos de correções atmosféricas existentes, o modelo denominado $6 \mathrm{~S}$ é considerado o mais embasado e robusto (Antunes et al., 2003; Novo, 2010; Almeida et al., 2015), uma vez que segundo Barboza (2005) apud Novo (2010) o método 6S corrige os efeitos de espalhamento, absorção atmosféricas e variações sazonais de irradiância solar.

Almeidaet al. (2015, p. 6862) apontam que o Modelo 6S apresenta a grande vantagem em relação ao método DOS (Dark Object Subtraction) quando trata-se da inserção de valores físicos, que subtrai o valor do pixel escuro: "A principal vantagem deste modelo é que ele também considera o processo de absorção da radiação eletromagnética, o que implica em valores de reflectância de superfície mais confiáveis".

A confiabilidade do modelo de conversão de Radiância Aparente em Reflectância de 
Revista Brasileira de Geografia Física v.11, n.04 (2018) 1458-1477.

Superfície é importante visto que esses valores são utilizados para a caracterização espectral dos alvos.As imagens digitais consistem em representações matriciais da superfície imageada e em seu formato original de distribuição apresentam um valor relativo para o pixel conhecido como Numero Digital (ND).

Ponzoni e Shimabukuro (2007, p. 69) apontam que nas imagens digitais "um valor de ND de uma imagem em uma banda específica, não está então na mesma escala de outro ND de outra imagem em outra banda espectral", ou seja, os valores de NDs são relativos, inviabilizando a comparação entre imagens de sensores ou datas diferentes, uma vez que "os números digitais existentes nas imagens orbitais são proporcionais a valores de Radiância que foram medidos por cada um dos detectores, em cada faixa ou banda espectral no qual o sensor atua" (Ponzoni e Shimabukuro, 2007, p. 43).

A produção de padrões de imagens (claro/escuro) é aparentemente consistente, mas se os alvos em questão apresentarem comportamento espectral muito semelhante essas pequenas diferenças tenderão a se perder. A solução da problemática da incompatibilidade entre os NDs das imagens é a conversão destes valores para valores físicos de radiância e reflectância de superfície, o que exige conhecimento quanto às características dos sensores, imagens e do ambiente na qual foi gerada essa imagem.

Santos et al. (2017) mapearam o uso e cobertura da terra em 9 municípios da região sul do estado do Tocantins, utilizaram neste trabalho imagens Landsat 5 e 8, com o objetivo de analisar a cobertura da terra nos anos de 1990, 2000, 2007 e 2015. Neste mapeamento utilizou-se de correção atmosférica. Os autores apontaram que o mapeamento foi classificado pelo Índice Kappa como Bom e os resultados indicaram nível elevado de antropização e conversão de áreas de Formação Savânica em áreas antropizadas. Dessa forma a aplicação da correção atmosférica auxiliou na resposta ao problema de pesquisa.

Índice de Vegetação da Diferença Normalizada NDVI - Dentre as possibilidades oferecidas pelo PDI, está a criação de índices por meio da realização de operações entre bandas espectrais.

Ponzoni e Shimabukuro (2007, p. 80). Apontam que a fundamentação do NDVI encontrase no fato da reflectância da vegetação ser inversamente proporcional entre as bandas do visível e do infravermelho próximo. "Em princípio, quanto maior for a densidade da cobertura vegetal em uma determinada área, menor será a reflectância na região do visível devido a maior oferta de pigmentos fotossintetizantes. Por outro lado, maior será a reflectância verificada na região do infravermelho próximo devido ao espalhamento múltiplo da radiação eletromagnética nas diferentes camadas de folhas"

Segundo Moreira (2012) dentre os índices de vegetação existentes o NDVI é o mais amplamente difundido quando se trata de analisar o vigor vegetativo. O NDVI de uma determinada área pode ser obtido através da seguinte equação (1) (Moreira, 2012).

$$
N D V I=\frac{I V P-V e r}{I V P+V e r}
$$

Em que NDVI = Índice de Vegetação da Diferença Normalizada, IVP = Reflectância da banda no Infravermelho Próximo e Ver $=$ Reflectância da banda no Vermelho.

A imagem NDVI pode ser utilizada isoladamente ou como uma das bandas para a elaboração de composições coloridas.

França et al., (2017) utilizaram o NDVI para caracterizar o grau de antropização no município paranaense de Clevelândia, e apontaram através dessa técnica três graus de antropização: alta, moderada e baixa, e reafirmam a importância da utilização do NDVI como "fonte de informação técnica para análises ambientais" e "mecanismo científico para elaboração de programas e políticas públicas de conservação, proteção, planejamento do uso do solo e dos recursos naturais no município e região." (FRANÇA et al., 2017, p. 282).

Definições e Aplicações do Spring - Para a realização de ajustes e correções como a retificação radiométrica utilizada para fins de mapeamento de uso e cobertura da terra, existe uma variedade de softwares disponíveis no mercado das geotecnologias. Contudo o alto custo do licenciamento desses softwares leva a necessidade de buscar alternativas mais acessíveis tanto no âmbito acadêmico quanto institucional (Órgãos Governamentais: Prefeituras, Secretarias de Meio Ambiente, etc.), uma vez que esse alto custo torna comum o emprego de software de $\mathrm{Cad} \mathrm{e}$ pirateamento de programas de alto custo.

Segundo Câmara et al. (1993, p. 308) "o Inpe, através de sua divisão de Processamento de Imagens, vem atuando desde 1972 na pesquisa e desenvolvimento na área de Geoprocessamento e Sensoriamento Remoto" desenvolvendo entre 1984e 1990 o Sistema de Tratamento de Imagens (Sitim) e o Sistema de Informação Geográfica (SIG) evoluindo em 1991 para a unificação dos dois 
Revista Brasileira de Geografia Física v.11, n.04 (2018) 1458-1477.

sistemas em um só através da criação do Sistema de Processamento de Informações Georreferenciadas (Spring) juntamente com a Embrapa Informática Agropecuária (Soares, 2001; Moreira, 2012).

Segundo Inpe (2017) um dos objetivos do Spring é oferecer um sistema de SIG brasileiro livre e gratuito de rápido aprendizado e grande capacidade de processamento para a utilização em "Agricultura, Floresta, Gestão Ambiental, Geografia, Geologia, Planejamento Urbano e Regional".

O Spring é capaz de armazenar um grande volume de dados podendo ser matriciais e vetoriais que "permitem armazenar de forma organizada e compacta diversos tipos de mapas temáticos, imagens aéreas, imagens de satélites e imagens de radar" (Rosa, 2005, p. 88). Sua estrutura é baseada num modelo de dados orientado a objetos advinda da sua interface com menus multi-janelas, atuando também em segmentação e classificação de imagens por regiões e geração de grades triangulares através da utilização de algoritmos inovadores (Rosa, 2005; Moreira, 2012).

A intensificação da utilização dessas técnicas empregadas no estudo dos recursos naturais tem proporcionado o desenvolvimento e o avanço da geoinformática possibilitando cada vez mais o lançamento de softwares voltados para análise espacial ambiental, viabilizando o controle e monitoramento dos recursos naturais e facilitando no processo de tomada de decisão dos gestores (Soares, 2001, 2001a; Francisco et al., 2015).

Existem vários estudos utilizando Spring e suas diversas aplicações para a análise dos aspectos ambientais. Maranhão et al (2017) utilizaram o Spring para correção de imagens e operações entre bandas do sistema RapidEye (Índice de Vegetação da Diferença Normalizada - NDVI - e Índice de Vegetação Ajustado ao Solo - SAVI) para caracterização do uso e cobertura a terra de Pinheiral (RJ). Brito e Leite (2015) utilizaram o Spring para diagnosticar o potencial natural erosivo dos solos da bacia Hidrográfica do Rio Água Suja, utilizando a LEGAL, disponível no módulo de Análise Espacial do SPRING, para efetivar os processos de ponderação e cruzamentos matriciais. Da Silva et al. (2010) realizaram no Spring o mapeamento das classes de uso da terra, dos tipos de solo e das classes de relevo para identificar as unidades de paisagem e realizar o zoneamento geoambiental da Bacia Hidrográfica do Açude Camará no Estado da Paraíba. Ferrari et al., (2009) aplicaram com o uso do Spring o Índice de Vegetação da Diferença Normalizada (NDVI) em imagens do satélite/sensor Cbers-2B/CCD para caracterizar e identificar áreas de pastagens degradadas no município de Camapuã, MS. Francisco et al., (2015), mapearam as áreas de maior aptidão agrícola de fruticulturas das terras do estado da Paraíba, e Resende et al., (2000, p. 04) utilizaram o Spring para mapear o desflorestamento da Amazônia combinando "técnicas de registro, tratamento, segmentação e classificação de imagens digitais" do satélite/sensor Landsat-TM.

\section{Material e Métodos}

Área de estudo - O municipio de Miranda, localizado na porção sudoeste do estado de Mato Grosso do Sul entre os pares de coordenadas $20^{\circ}$ $29^{\prime}$ sul, $57^{\circ} 01^{\prime}$ oeste e $19^{\circ} 39^{\prime}$ sul e $56^{\circ} 11^{\prime}$ oeste, possui área de $5.478,82 \mathrm{~km}^{2}$, seus limites fazem divisa com os muncípios de Aquidauana, Anastácio, Bodoquena, Bonito e Corumbá (Figura $1)$.

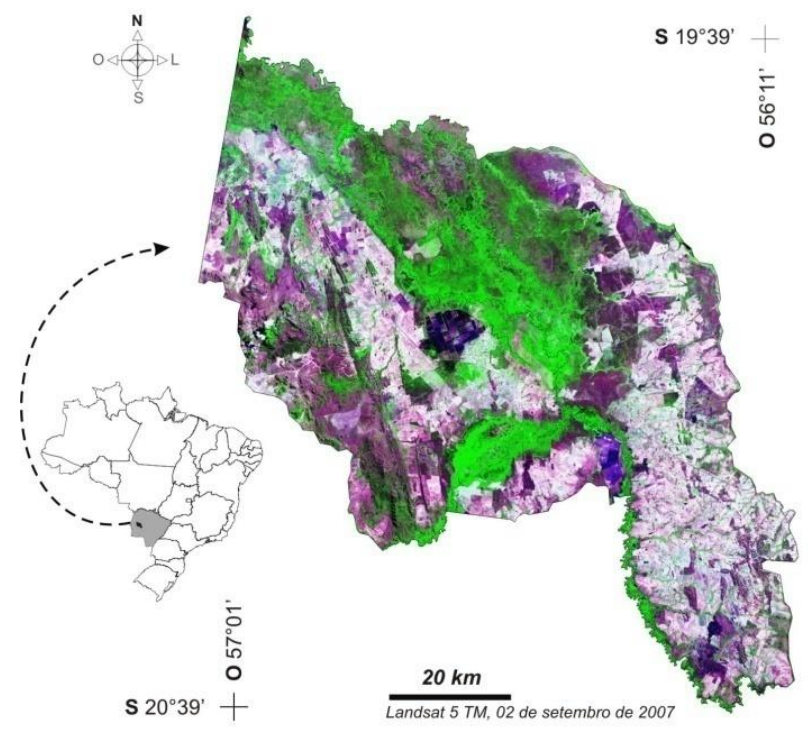

Figura 1. Localização da área de estudo.

Sua economia gira em torno dos serviços, administração pública e da atividade agropecuária, com ênfase na produção de arroz irrigado e pecuária bovina. Em 2016 a lavoura temporária de Arroz Irrigado produziu 30.617 toneladas em 4.867 hectares de área colhida. $\mathrm{Na}$ atividade pecuária, a mais expressiva é o manejo com bovinos, tendo no município em 2016 um rebano com 376.000 cabeças de gado (IBGE, 2017a, 2017b).

A sua população segundo IBGE (2010) são de 25.595 habitantes, dos quais 1876 hab. no ano de 2013 cupavam o setor de serviços, 881 agricultura e 855 o setor da indústria e comércio (IBGE, 2017).

O município de Miranda no contexto da Bacia do Alto Paraguai (BAP) e do Pantanal - A bacia do Alto Paraguai, onde está inserido o 
Revista Brasileira de Geografia Física v.11, n.04 (2018) 1458-1477.

Pantanal, abrange o território de países sulamericanos: Bolívia, Brasil e Paraguai. Na porção brasileira, abarca parte do estado de Mato Grosso e do estado do Mato Grosso do Sul. No Brasil, sua área é de $361,666 \mathrm{Km}^{2}$ estando o Pantanal ocupando $138,183 \mathrm{Km}^{2}$ na bacia totalizando $38,21 \%$ de sua área (PCBAP, 1997).

Segundo o WWF Brasil (2015) a BAP encontra-se na presença de três grandes Biomas, a Amazônia, o Cerrado e o Pantanal, apresentando também áreas de encrave de Mata Atlântica. Seu relevo é marcado pelo contraste entre terras inundáveis periodicamente pela dinâmica que acontece no Pantanal e terras não inundáveis, correspondendo à borda de bacia formada por planaltos, serras e depressões onde se encontram grande parte das nascentes dos rios da bacia (PCBAP, 1997).

Segundo Ab'sàber (2006), a Bacia do Alto Paraguai, como grande anfiteatro de erosão, tem seus principais rios nascendo nas áreas de Planalto e rios Alóctones que chegam ao Pantanal, trazendo sedimentos e poluentes, como os agrotóxicos. Esse quadro é oriundo da: "exploração intensiva do planalto por atividade de pecuária e de agricultura associada à conversão de Ấreas Naturais para Áreas Antrópicas favorecem a ocorrência de processos erosivos e o assoreamento dos cursos fluviais no próprio planalto e, especialmente, na planície, dadas as condições hidrodinâmicas dos cursos d'água" (WWF-Brasil, 2015, p.02). Essas alterações ocorreram ao longo dos anos em virtude principalmente da "demanda econômica pela substituição da vegetação nativa para a formação de pastagens e agricultura" (WWF Brasil,2015, p. 02).

Sua dimensão e suas características físicoterritoriais exigem importantes ações e estratégias de monitoramento e gerenciamento de recursos da bacia. Devido a isso, agências governamentais têm levantado dados e construído materiais que possibilitem identificar, diagnosticar, prever e sugerir ações que possam mitigar problemas como para a poluição e degradação das águas, do solo, perda da biodiversidade e das riquezas econômicas e sociais impedindo o avanço dos conflitos pelo uso da água e estimulando a criação de ferramentas de gestão dos recursos hídricos (ANA, 2004).

Nesse contexto, o município de Miranda representa grande parte dessas características encontradas na Bacia do Alto Paraguai (Figura 2). Seu relevo corresponde tanto a planície do pantanal Aquidauana-Miranda com as cotas mais baixas de altimetria na sua porção norte e as terras mais altas correspondendo a leste pela depressão de Miranda e a sudoeste com a topografia caracterizada pela região da Bodoquena onde encontramos a unidade geomorfológica Serra da Bodoquena.

A vegetação predominante é formada por contatos florísticos entre Cerrado e remanescentes do Bioma Mata Atlântica, contato Cerrado e Chaco e formações do tipo Floresta Estacional, Estacional Decidual e Estacional Semidecidual e Cerrado (Mato Grosso do Sul, 2011).

No município verifica-se a presença de manchas expressivas de Argissolos, Chernossolos e Vertissolos encontradas respectivamente na região da depressão de Miranda e na região da Bodoquena cujo relevo é mais acentuado e no pantanal de Miranda. Ocorrem ainda em manchas menores Gleissolos, Neossolos, Planossolos e Plintossolos (PCBAP, 1997; Mato Grosso do Sul, 2011; Leite e Leite, 2016).

A geologia do município é caracterizada por apresentar rochas do Período Pré-Cambriano como do Complexo Rio Apa, do Grupo Corumbá com a Formação Puga, Formação Cerradinho com presença de calcário calcítico e calcário dolomítico, Formação Bocaína e rochas do Grupo Cuiabá com presença de Filitos, Mármore e Xisto na região da Bodoquena a sudoeste e na depressão do Miranda a leste e pequenas manchas de xistos, filitos e quartizitos da Unidade Metavulcano-Sedimentar Rio Bacuri na depressão de Miranda. Também verifica-se a ocorrência de rochas do Período Pleistoceno com a ocorrência da Formação Pantanal com fácies depósitos aluvionares na região do Pantanal de Miranda com pequenos fragmentos de fácies terraços aluvionares na região da Bodoquena (Mato Grosso do Sul, 1990; PCBAP, 1997; CPRM, 2006; Mato Grosso do Sul, 2011). 


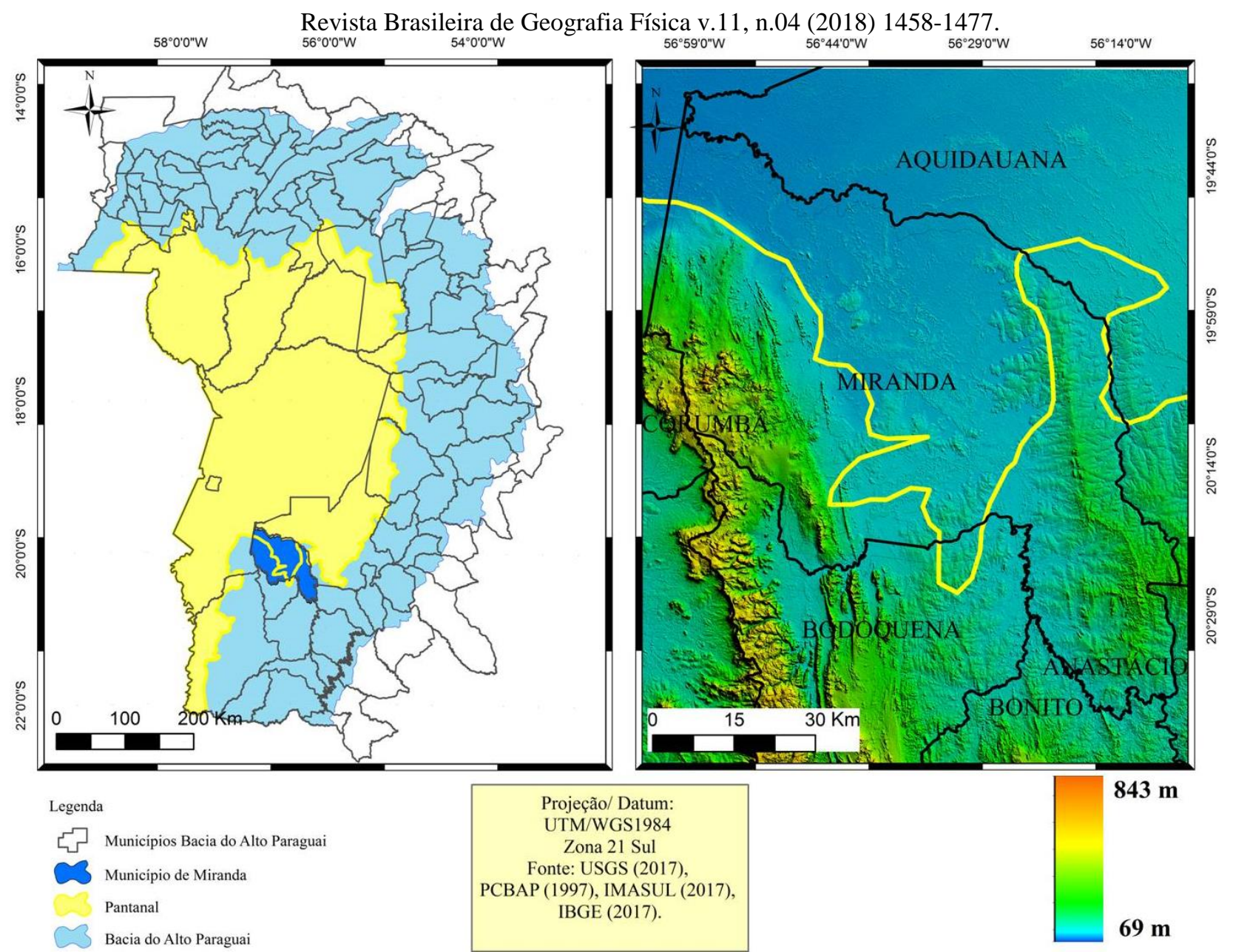

Figura 2. Localização do município de Miranda na Bacia do Alto Paraguai - BAP.

O clima no município de Miranda, conforme classificação de Köppen, é Aw com clima tropical e estação chuvosa no verão durante o período de novembro a abril e estação seca no inverno de maio a outubro, sendo julho o mês mais seco (Figura 3).

Climograma do Município de Miranda, MS

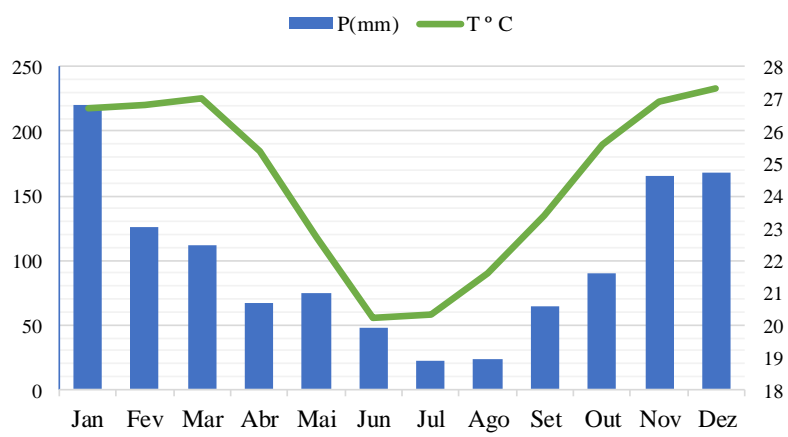

Figura 3. Climograma do Município de Miranda, MS.

Fonte: Adaptado de Gonçalves et al., (2009).

O mês mais frio apresenta temperatura média que variam entre $14^{\circ}$ e $15^{\circ} \mathrm{C}$, oscilando entre Quadro 1. Características das imagens do Sensor TM do Satélite Landsat 5 $4^{\circ}$ e $6^{\circ}$ nas temperaturas mínimas absolutas. A precipitação média anual varia entre $750 \mathrm{~mm}$ a $1800 \mathrm{~mm}$ (Gonçalves et al., 2006; Carvalho Junior et al, 2009).

\section{Material e Métodos}

Imagens do Projeto Landsat -As imagens utilizadas para elaboração dos mapas de Uso e Cobertura da Terra contidas neste trabalho encontram-se disponibilizadas de forma gratuita no site da United States Geological Survey (USGS) e fazem parte do Projeto Landsat.Para o mapeamento dos anos de 2006 e 2011 foram utilizadas imagens do Sensor TM, do satélite Landsat 5, e para o ano de 2017 foi utilizada uma imagem do Sensor OLI, do satélite Landsat 8.

As imagens de ambos os satélites utilizados tiveram a mesma órbita/ponto: 226/74, sendo que as datas de aquisição foram as seguintes: 30 de Agosto de 2006; 29 de Setembro de 2011, e 13 de setembro de 2017. Os quadros 1 e 2 apresentam as características de Resolução Espectral e Espacial das imagens Landsat 5-TM e 8-OLI.

Leite, V. A. W. Rodrigues, L. P., Leite, E. F. 
Revista Brasileira de Geografia Física v.11, n.04 (2018) 1458-1477.

\begin{tabular}{|l|l|l|}
\hline Bandas Espectrais & Faixas Espectrais & Resolução Espacial (m) \\
\hline 1 (azul) & $450-520 \mathrm{~nm}$ & $30 \mathrm{~m}$ \\
\hline 2 (verde) & $520-600 \mathrm{~nm}$ & $30 \mathrm{~m}$ \\
\hline 3 (vermelho) & $630-690 \mathrm{~nm}$ & $30 \mathrm{~m}$ \\
\hline 4 (infravermelho próximo) & $760-900 \mathrm{~nm}$ & $30 \mathrm{~m}$ \\
\hline 5 (infravermelho médio) & $1550-1750 \mathrm{~nm}$ & $30 \mathrm{~m}$ \\
\hline 6 (termal) & $1040-1240 \mathrm{~nm}$ & $120 \mathrm{~m}$ \\
\hline 7 (infravermelho distante) & $2080-2350 \mathrm{~nm}$ & $30 \mathrm{~m}$ \\
\hline
\end{tabular}

Fonte: Adaptado de USGS (2017a).

A largura da faixa imageada (nadir) de 185 $\mathrm{km}$ e resolução temporal de 16 para ambos os sensores, sendo que o Landsat 8 possui Resolução Radiométrica de 16bit e o Landsat 5 tem Resolução
Radiométrica de 8bit (USGS, 2017b; 2017c), por esse motivo as imagens do sensor OLI foram convertidas durante a importação para o banco de dados em imagens de 8bits.

Quadro 2. Características das imagens do Sensor OLI do Satélite Landsat 8

\begin{tabular}{|l|l|l|}
\hline Bandas Espectrais & Faixas Espectrais & Resolução Espacial (m) \\
\hline 1 (Coastal aerosol) & $430-450 \mathrm{~nm}$ & $30 \mathrm{~m}$ \\
\hline 2 (Azul) & $450-510 \mathrm{~nm}$ & $30 \mathrm{~m}$ \\
\hline 3 (Verde) & $530-590 \mathrm{~nm}$ & $30 \mathrm{~m}$ \\
\hline 4 (Vermelho) & $640-690 \mathrm{~nm}$ & $30 \mathrm{~m}$ \\
\hline 5 (Infravermelho próximo) & $850-880 \mathrm{~nm}$ & $30 \mathrm{~m}$ \\
\hline 6 (Infravermelho médio) & $1570-1650 \mathrm{~nm}$ & $30 \mathrm{~m}$ \\
\hline 7 (Infravermelho distante) & $2110-2290$ & $30 \mathrm{~m}$ \\
\hline 8 (Pancromático) & $1360-1380 \mathrm{~nm}$ & $15 \mathrm{~m}$ \\
\hline 9 (Cirrus) & $500-680 \mathrm{~nm}$ & $30 \mathrm{~m}$ \\
\hline
\end{tabular}

Fonte: Adaptado de USGS (2017).

As bandas utilizadas nesse mapeamento foram para o Landsat 5-TM: 3 (Vermelho), 4 (Infravermelho Próximo) e 5 (Infravermelho Médio); e para o Landsat 8-OLI: 4 (Vermelho), 5 (Infravermelho Próximo) e 6 (Infravermelho Médio). A imagem a seguir (Figura 4) apresenta uma comparação entre as bandas espectrais, através da qual é possível aferir as semelhanças e diferenças entre os intervalos espectrais das imagens TM e OLI, observa-se que as bandas do Landsat 8-OLI apresentam maior resolução espectral, cobrindo regiões menores do espectro eletromagnético.

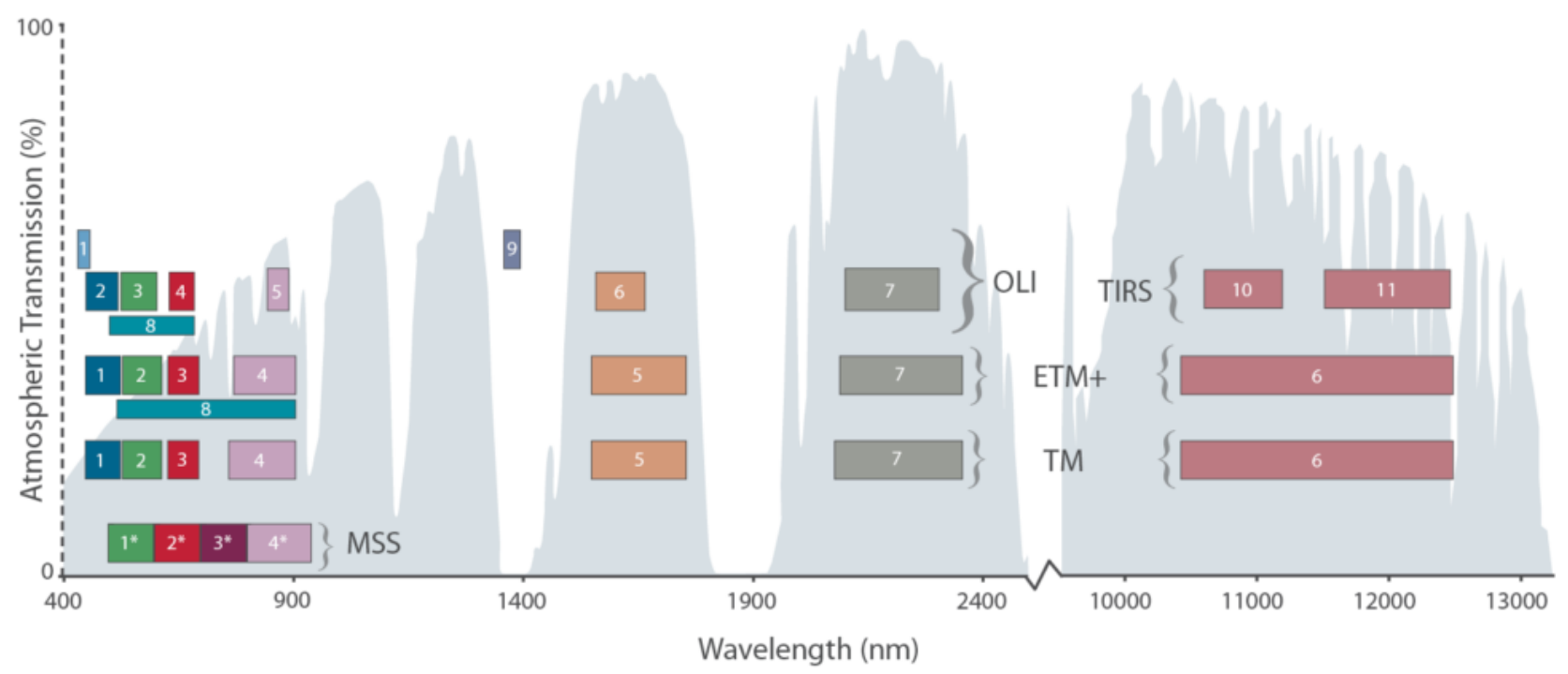

Figura 4. Comparação entre as bandas espectrais dos sensores TM e OLI dos satélites Landsat 5 e 8. Fonte: USGS (2017d). 
Revista Brasileira de Geografia Física v.11, n.04 (2018) 1458-1477.

Modelo Digital de Elevação - No Spring, "a representação da superfície real no computador é feita através de grades ou malhas, criando um modelo digital" de Terreno (Soares, 2001a, p. 02) gerando "uma representação matemática da distribuição espacial de uma determinada variável em uma superfície contínua" (Soares, 2001a, p. 02). O Modelo Numérico de Terreno (MNT) ou Modelo Digital de Terreno (MDT) "é o dado resultante da reconstrução com ferramentas computacionais e representação artificial" de uma dada região (Moreira, 2012, p. 213). O MNT pode ser utilizado para "representar ou espacializar altitude, $\mathrm{pH}, \mathrm{Ca}$, Mg, etc." (Soares, 2001a, p. 07).

Os MNTs utilizados para representar dados altimétricos podem ser denominados MDE (Modelo Digital de Elevação). Esses dados são obtidos por sensores não imageadores que "se caracterizam por não serem configurados para fornecer uma imagem bidimensional do terreno" (Novo, 2010, p. 87). Os dados originados combinados com técnicas de geoprocessamento são responsáveis por caracterizar as variáveis do relevo como "altitude, declividade, curvaturas vertical e horizontal, orientação de vertentes etc." (Valeriano, 2008, p. 72).

Os dados altimétricos do sensor Shuttle Radar Topographic Mission (SRTM) realizado em fevereiro de 2000 e disponibilizado gratuitamente pela USGS, com resolução de $\sim 30 \mathrm{~m}$ para os Estados Unidos e $\sim 90 \mathrm{~m}$ para o restante do mundo são muito utilizados para a extração da variável declividade (Valeriano, 2008).

Segundo Valeriano (2008a) a resolução espacial original dos dados foram refinados pelo projeto Topodata pelo método de interpolação por krigagem corrigindo os dados ausentes e convertendo a resolução espacial de $\sim 90 \mathrm{~m}$ para $\sim 30 \mathrm{~m}$, foram também aplicados algoritmos de análise geomorfométrica para o cálculo das variáveis declividade, orientação de vertentes, curvatura horizontal e curvatura vertical, disponibilizados publicamente pelo Inpe.

Neste trabalho foram utilizadas as quadriculas s20_w057, s20_w058, s21_w057 e s21_w058 para a elaboração da declividade da área de estudo.

\section{Procedimentos metodológicos}

Mapas de uso e cobertura da terra -O Processamento Digital das imagens Landsat 5-TM e Landsat 8-OLI foi realizado no aplicativo de SIG Spring(Câmara et al..1996), versão 4.3.3, onde montou-se um banco de dados geográficos, no qual foram inseridas as imagens correspondentes aos anos de 2006, 2011 e 2017.

Seguiram-se os procedimentos metodológicos de Moreira (2012), no qual as imagens passaram pelo Pré-processamento, em que foram aplicadas técnicas que melhorassem a qualidade visual e radiométrica das imagens.

A Correção Atmosférica seguiu a metodologia de Ponzoni e Shimabukuro (2007)que afirma que está deve ser elaborada em duas etapas, em que os valores dos ND's são convertidos para valores físicos de Radiância Aparente e na segunda etapa os valores de Radiância Aparente devem ser convertidos para valores de Reflectância de Superfície.

$\mathrm{Na}$ primeira etapa, da Retificação Radiométrica/Correção Atmosférica,conforme Ponzoni e Shimabukuro (2007), empregou-se a fórmula de Markham e Barker (1986), e na segunda etapa optou-se pelo emprego do método 6S (Second Simulation of Satellite Signal in the Solar Spectrum), de Vermote et al., (1997).

A partir da correção atmosférica observouse uma modificação considerável nos resultados obtidos referentes à caracterização espectral dos alvos.Notou-se que os valores de Refletância de Superfície são os mais semelhantes aos padrões de caracterização de comportamento espectral de alvos descritos por Novo (2010).

Foram empregadas também durante o Préprocessamento, as técnicas de Realce de Histograma, Recorte de imagens, e obtenção do índice de vegetação denominado Normalized Difference Vegetation Índex(NDVI) através da utilização das Operações Aritméticas, o qual durante a aplicação da composição colorida Falsa cor, foi empregado para a cor verde, que busca destacar a vegetação(Moreira, 2012). A composição colorida utilizada, foi portanto:

- Landsat 5-TM: R(5)G(NDVI)B(3)

- Landsat 8-OLI:R(6)G(NDVI)B(4).

A figura5 demonstra a diferença entre a imagem Landsat 5, com composição colorida A: $\mathrm{R}(5) \mathrm{G}(4) \mathrm{B}(3)$; e B: R(5)G(NDVI)B(3): 
Revista Brasileira de Geografia Física v.11, n.04 (2018) 1458-1477.
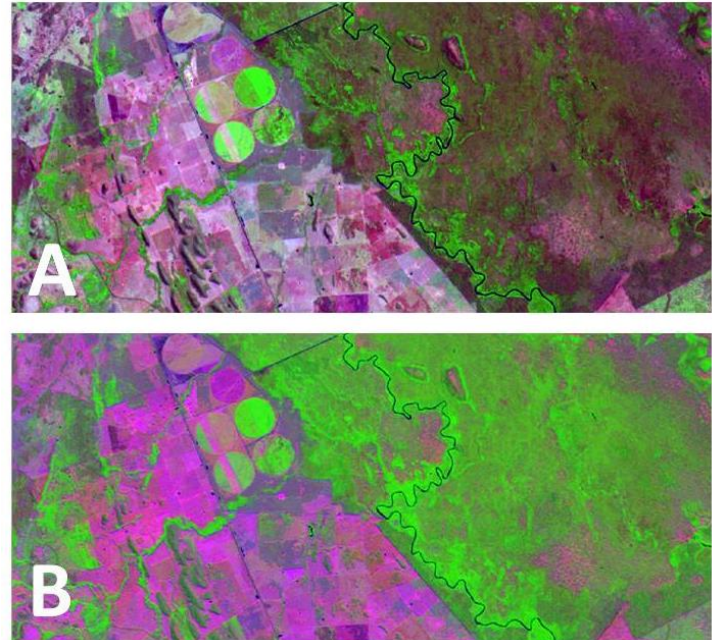

Figura 5. Diferença entre a imagem Landsat 5, com composição colorida A: R(5)G(4)B(3); e B: $\mathrm{R}(5) \mathrm{G}(\mathrm{NDVI}) \mathrm{B}(3)$.

A Classificação das imagens seguiu o Método Híbrido (Moreira, 2012), onde aplicou-se a segmentação da imagem, com limiar 10 e similaridade 30. O classificador adotado foi o Isoseg, e as classes estabelecidas foram adaptadas do Manual de Uso e Cobertura da Terra do IBGE (2013). A fim de maior acurácia da classificação realizou-se a edição matricial.

Mapa de declividade - A declividade do terreno foi compilada do trabalho de Leite e Leite (2016)para a mesma área de estudo cuja elaboração consistiu na utilização de dados altimétricos do projeto Topodata calculados no software Spring de acordo com os procedimentos descritos por Leite e Rosa (2012).

\section{Resultados e Discussão}

Foram analisadas seis classes temáticas de uso e cobertura da terra para os anos de 2006, 2011 e 2017 (Tabela 1), sendo Remanescentes Florestais, Campo/Pasto, Cicatriz de Queimada, Agricultura Irrigada, Área urbana - Miranda e Córpos D'água. Para o ano de 2006 (Figura 6)verifica-se que na maior parte do município a cobertura se caracteriza por "Campo/Pasto",apresentando uma área de $3.042,48 \mathrm{~km}^{2}$ o que corresponde a $55,53 \%$ da área total.São áreas com baixa declividade, notadamente na depressão de Miranda e nasproximidades da Serra da Bodoquena, de uso essencialmente pela prática da pecuária extensiva (Figura 7).

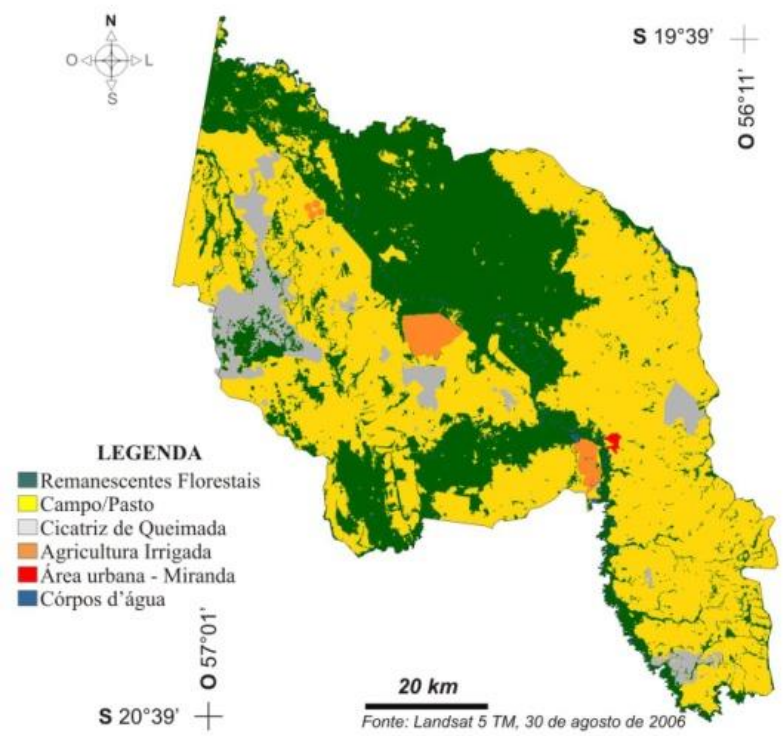

Figura 6. Mapa de uso e cobertura da terra no município de Miranda no ano de 2006.

Considerando a área ocupada, a segunda com maior expressão foi a classe de "Remanescentes Florestais". Com 37,09\% da área de estudo, concentra-se sobretudo na planicie pantaneira, área sujeita a inudação sazonal. Verifica-se também fragmentos menores nas proximidades da região da Serra da Bodoquena e ao longo do curso do rio Miranda.

São características destas áreas, a prática da pecuária que estimula a abertura de novas áreas para a implantação de pastagens. Há uma associação do padrão espacial retangular das áreas, aos grandes produtores agropecuários que ocupam vastas áreas de vegetação nativa para a execução de suas atividades econômicas (Gavlak et. al., 2013).

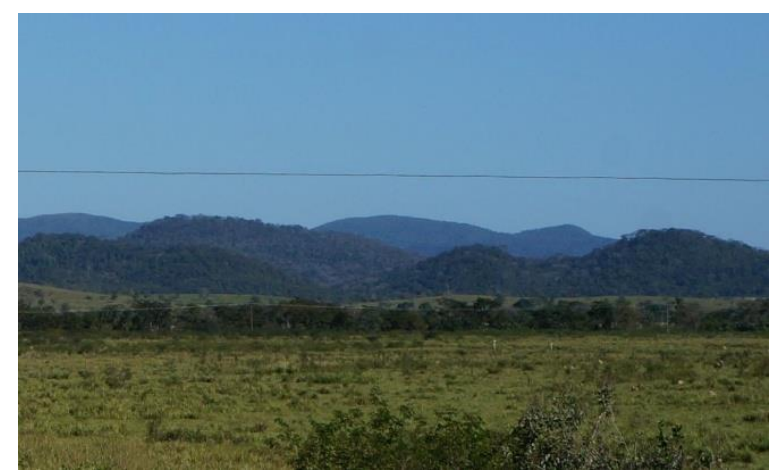

Figura 7. Pastagens em primeiro plano e Serra da Bodoquena ao fundo.

O uso do fogo de forma indiscriminada também tem levado a alteração da cobertura vegetal (Padovani et. al., 2004). Como a queima de pasto para renovação é uma prática comum na região, a classe temática"Cicatriz de Queimada" foi verificada nas imagens analisadas. No ano de 2006 correspondeu a 5,57\% da área do município de 
Revista Brasileira de Geografia Física v.11, n.04 (2018) 1458-1477.

Miranda, sendo $305,15 \mathrm{~km}^{2}$. Foram verificados várias cicatrizes de queima ao longo de áreas de Campo/Pasto, sendo um maior situada na região da Serra da Bodoquena.Cicatrizes de queima menores estão dispersas na depressão do Miranda e na região de contato florístico Cerrado/Mata Atlântica.

As classes de“Agricultura Irrigada", os representaram os menores valores de área de uso e cobertura encontrados, correspondendo a1,46\% $\left(79,79 \mathrm{~km}^{2}\right), 0,26 \%\left(14,40 \mathrm{~km}^{2}\right)$ e $0,09 \%\left(4,90 \mathrm{~km}^{2}\right)$ respectivamente.

"Corpos D’água" e a "Área Urbana - Miranda"

Tabela 1. Representatividade das classes de uso e cobertura da terra no município de Miranda, MS nos anos de 2006, 2011 e 2017.

\begin{tabular}{|c|c|c|c|c|c|c|}
\hline \multirow[b]{2}{*}{ Classe Temática } & \multicolumn{2}{|c|}{ Agosto de 2006} & \multicolumn{2}{|c|}{ Setembro de 2011} & \multicolumn{2}{|c|}{ Setembro de 2017} \\
\hline & $\mathbf{K m}^{2}$ & $\%$ & $\mathbf{K m}^{2}$ & $\%$ & $\mathbf{K m}^{2}$ & $\%$ \\
\hline Cicatriz de Queimada & 305,15 & 5,57 & 1,43 & 0,03 & 7,28 & 0,13 \\
\hline Remanescentes Florestais & $2.032,10$ & 37,09 & $2.773,47$ & 50,62 & $2.179,98$ & 39,79 \\
\hline Campo/Pasto & $3.042,48$ & 55,53 & $2.599,37$ & 47,44 & $3.193,21$ & 58,28 \\
\hline Corpos D’água & 14,40 & 0,26 & 23,14 & 0,42 & 18,29 & 0,33 \\
\hline Área Urbana - Miranda & 4,90 & 0,09 & 4,90 & 0,09 & 5,06 & 0,09 \\
\hline Agricultura Irrigada & 79,79 & 1,46 & 76,51 & 1,40 & 75,00 & 1,37 \\
\hline Total & $5.478,82$ & 100 & $5.478,82$ & 100 & $5.478,82$ & 100 \\
\hline
\end{tabular}

Fonte: Elaborado pelos autores.

No ano de 2011 (Figura 8) houve uma reduçao em área ocupada pela classe temática "Campo/Pasto". Na análise verificou-se uma redução de $443,11 \mathrm{~km}^{2}$ de agosto de 2006 para setembro de 2011. Em contrapartida houve duas classes que apresentaram aumento em área ocupada. No caso, os "Remanescentes Florestais" somaram $741,37 \mathrm{~km}^{2}$ e os "Corpos D'Água"passaram de $14,40 \mathrm{~km}^{2} \quad(0,26 \%)$ para $23,14 \mathrm{~km}^{2}(0,42 \%)$ em comparação com o ano de 2006.

Silva et al. (1998) atribui ao fator hidrológico, o principal fator regulador da vida e da ocupação no Pantanal, através de seus ciclos irregulares de inundação, como sendo o responsável pela conservação do Pantanal.

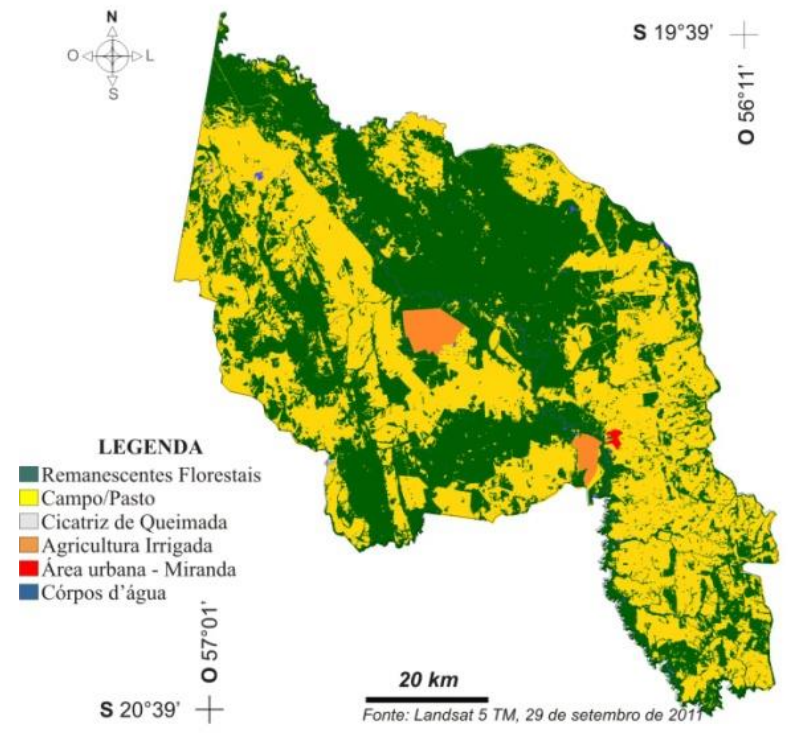

Figura 8. Mapa de uso e cobertura da terra no município de Miranda no ano de 2011.
Áreas de "Cicatriz de Queimada" diminuíram em área, partindo de $305,15 \mathrm{~km}^{2}$ $(5,57 \%)$ em 2006 para 1,43 (0,03\%) em 2011. As classes temáticas de "Agricutura Irrigada" e "Área Urbana - Miranda" apresentaram pouca variação em suas áreas no mesmo comparativo.

Em 2017 (Figura 9) houve uma ampliação nas áreas de Campo/Pasto em 5\%, chegando a $3.193,21 \mathrm{~km}^{2}(58,28 \%)$, comparando ao ano de 2011.

O processo de mudança de cobertura do solo mais intenso são verificados nos Pantanais que apresentam maior facilidade de acesso, como no caso de Aquidauana e Miranda, em MS, conforme verificado por Paranhos Filho et. al. (2014). Nessas áreas, a ocupação está transformando as formações florestais, como as cordilheiras e capões, em pastagens, como a braquiária. 
Revista Brasileira de Geografia Física v.11, n.04 (2018) 1458-1477.

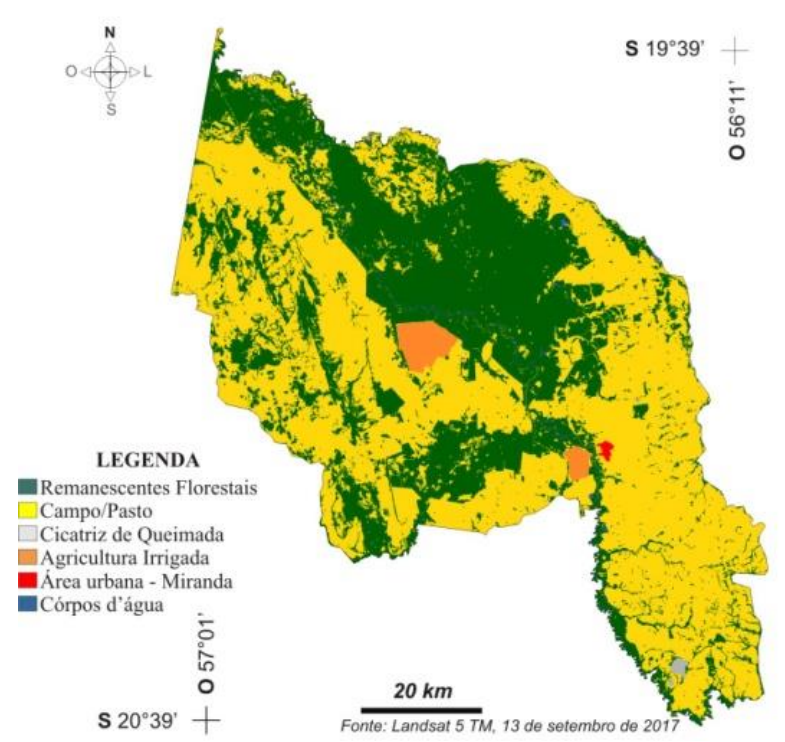

Figura 9. Mapa de uso e cobertura da terra no município de Miranda no ano de 2017.

A "Área Urbana - Miranda" e "Cicatriz de Queimada" também apresentaram crescimento quando comparados a 2011, atingindo $5,06 \mathrm{~km}^{2}$ $(0,09 \%)$ e $7,28 \mathrm{~km}^{2}(0,13 \%)$, respectivamente.As classes de "Agricultura Irrigada", "Corpos D'água" e "Remanescentes Florestais" apreentaram decréscimo (Figura 10).

A "Agricultura Irrigada" apresentou redução em $1,51 \mathrm{~km}^{2}$, atingindo $75 \mathrm{~km}^{2}$, ou $1,37 \%$ da área total. $\mathrm{O}$ que pode explicar a sensível redução em área, conforme a Conab (2013) é que nas últimas safras, nos estados do GO, do MS e de MT, identificou-se significativa redução de área de arroz em substituição pela cultura da soja, que tem apresentado maiores rentabilidades.

Os "Corpos D'água" apresentaram diminuiçãoem $0,09 \%$, chegando a $18,29 \mathrm{~km}^{2}$, ou $0,33 \%$ da área do município. "Remanescentes Florestais" neste ano ocuparam $2.179,98 \mathrm{~km}^{2}$, correspondente a 39,79\% do município de Miranda.
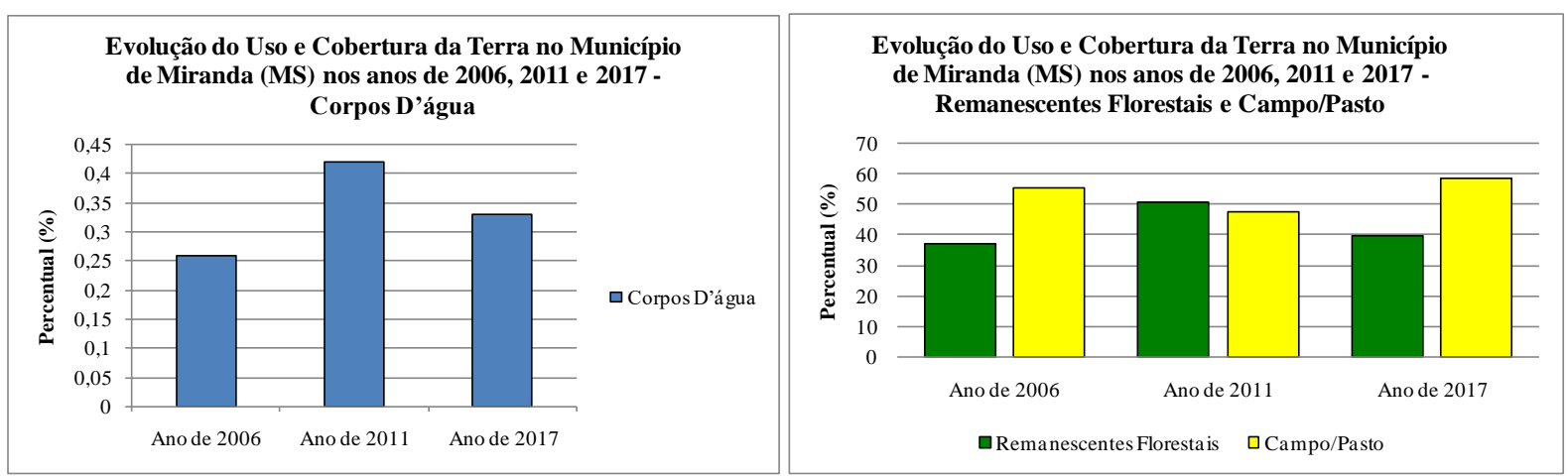

Figura 10.Evolução do Uso e Cobertura da Terra: Classes Corpos D'agua, Remanescentes Florestais e Campo/Pasto nos anos de 2006, 2011 e 2017.

O mapa de declividade (Figura 11) da área de estudo apresentou de acordo com as classes estabelecidas,clinografia do terreno entre valores menores que $6 \%$, de 6 a $12 \%$, de 12 a $20 \%$ e maior que $20 \%$. Verificou-se a maior ocorrência de área ocupada pela classe de intervalo de 0 a $6 \%$ de declividade $(79,78 \%$ de área).São áreas correspondentes a planície pantaneira e a depressão do Miranda, com terreno plano a suave ondulado. Ainda, $14,55 \%$ da área apresentaram declividades em torno de 6 a 12\%, notadamente áreas de transição topográfica, como terrenos moderadamente ondulados.

Terrenos ondulados perfazem apenas $2,86 \%$ da área, apresentando declives em torno de 12 a 20\%.Declividades superiores a 20\% representam apenas $2,80 \%$ da área do município, correspondendo a áreas fortemente onduladas. Estas últimas se concentram a sudoeste do município, na região da Serra de Bodoquena e região conhecida como serrinha, a sudeste no limite com o município de Aquidauana.

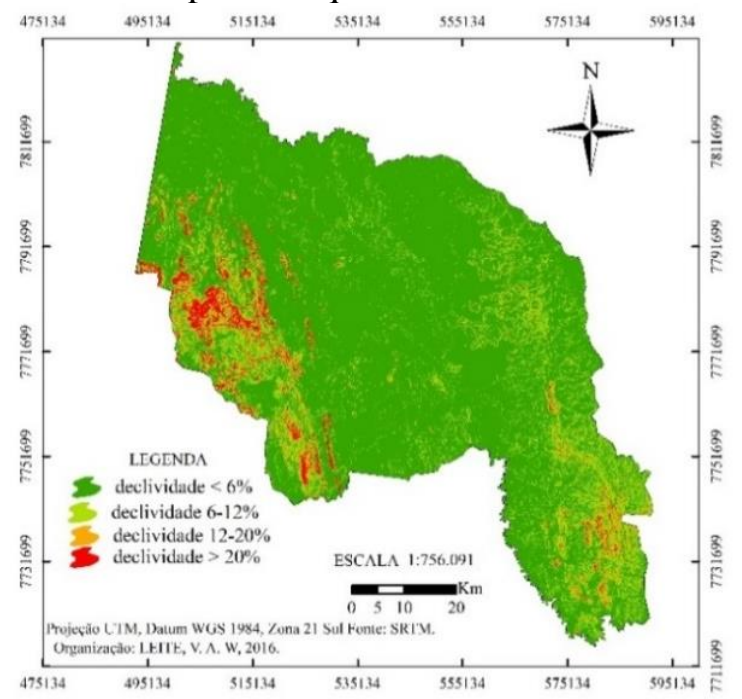

Figura 11. Mapa de declividade do município de Miranda, MS.

Fonte: Leite e Leite, (2016). 
Revista Brasileira de Geografia Física v.11, n.04 (2018) 1458-1477.

Os resultados obtidos nesta pesquisa estão em consonância com os resultados apresentados em trabalhos anteriores de pesquisadores como Mendes et al., (2009), que utilizaram a metodologia do Modelo Linear de Mistura Espectral para a análise do desmatamento no Município de Miranda nos anos de 1999 e 2009, esses autores também utilizaram, assim como neste trabalho, o classificador Isoseg com parâmetros de limiar 8 e similaridade 32. Como resultado os autores constataram que no período analisado houve um desmatamento de uma área de $460 \mathrm{~km}^{2}(8,4 \%$ do município), sendo que as áreas com maiores índices de desmatamento corresponderam as regiões Sudeste e Nordeste do município, próximas ao limite como o município de Aquidauana, áreas na região central do município que margeiam a $B R$ 262 a sudoeste.

Essas áreas de desmatamento demonstradas por Mendes et al.(2009) correspondem às áreas de Cerrado e Mata Atlântica, das quais identificou-se que as áreas vegetadas foram substituídas por pastagens em sua maioria, mas também pela cultura do Arroz (em menor escala).Nas áreas abrangidas pelo Pantanal, nota-se uma fragmentação crescente da vegetação nativa. Em 2006 observa-se uma vegetação mais coesa, enquanto que em 2017 há presença de áreas desmatadas tanto nas bordas quanto na área mais central do Pantanal, sub-região de Miranda.

Carvalho Junior et al. (2009)no estudo que realizou o Zoneamento Agroecológico do município de Miranda-MS verificaram que no ano de 2009 o município de Miranda apresentava mais de $62 \%$ de sua área com vegetação natural preservada, cerca de $3.400 \mathrm{~km}^{2}$, sendo que no restante do município, removeu-se ao longo dos anos a vegetação natural para substituí-las por pastagem, cobrindo nesse período $38 \%$ de sua área. Crispim et al., (2013) analisaram as áreas desmatadas entre os anos de 1994 a 2007 no município utilizando como base o número de autorizações obtidas para o desmatamento ou substituição de pasto nativo para o plantio de forrageiras exóticas, visto que estas melhor atendem a demanda da produção pecuária no estado. Os autores identificaram 185 autorizações emitidas, concentradas em maior número entre o período de 2000 a 2005, o que sugere que para o ano de 2006 houve uma maior fragmentação dos remanescentes de vegetação nativa primária.

Nesse mesmo ano houve de acordo com o CPTEC (2006) para a região centro-oeste no mês de agosto " 25 dias com ausência de chuvas significativas (acima de $1 \mathrm{~mm}$ ) na maior parte da Região. Contudo, esta situação de baixa pluviosidade corresponde ao período normal de estiagem, o que resultou em anomalias ligeiramente negativas". Para Crispimet al., (2013) "anos mais secos na região Pantaneira é um fator favorável para a introdução de espécies exóticas”, esse fator associado com desmatamento das propriedades agropecuárias justificam a maior representatividade da classe Campo/Pasto no ano de 2006 e a fragmentação da vegetação no Pantanal do município de Miranda identificada no mapeamento do uso e cobertura da terra para o ano de 2011 realizado neste trabalho.

Outra variável importante a ser ressaltada para a discussão do mapeamento do ano de 2011 é o aumento da precipitação durante o período de seca para o município de Miranda, ocorrendo um pico de elevação para o mês de setembro conforme demonstrado no gráfico da Figura 12. Em um período adjacente a setembro ocorreu em 1998 "uma inundação atípica pelo rio Miranda de trechos localizados a jusante da cidade de Miranda, alagando parte da obra em construção do Gasoduto Bolívia-Brasil (Gasbol)" (Galdino e Silva, 2006, p. 69).

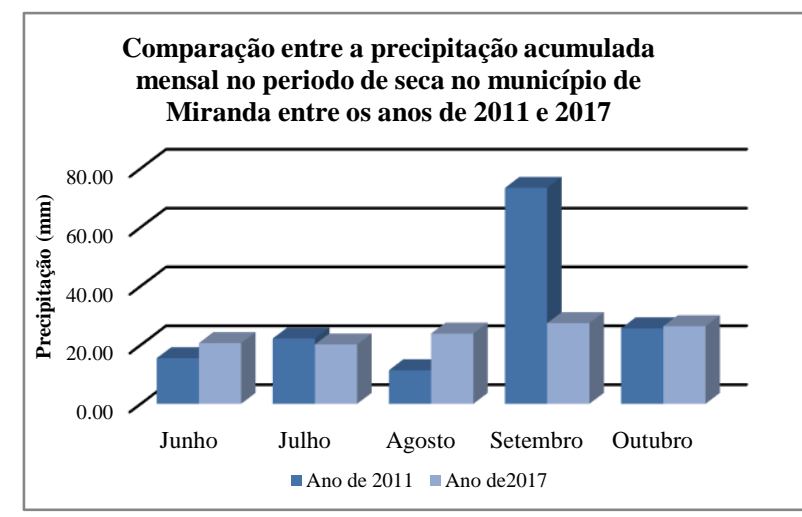

Figura 12. Comparação entre precipitação acumulada mensal no período de seca no município de Miranda entre os anos de 2011 e 2017.

$\begin{array}{ccc}\text { Essa } & \text { excepcionalidade } & \text { justifica } \\ \text { substancialmente } & \text { o aumento da classe }\end{array}$ "Remanescentes Florestais" e "Corpos D' água" no ano de 2011, a inundação ocorrida em 1998 reforça a ideia de que a cheia de 2011 tenha desencadeado uma possível regeneração da vegetação do município nesse período (sendo ressaltada pelo NDVI aplicado, que acentua os diferentes graus de vigor vegetativo) visto que no mapeamento realizado por Mendes et al. (2009) no ano subsequente ao da inundação de 1998, no ano de 1999 observa-se a presença de vegetação em maior proporção no município.

Silva et. al. (1998) observa que na várzea esquerda do rio Miranda, observam-se as duas 
Revista Brasileira de Geografia Física v.11, n.04 (2018) 1458-1477.

únicas áreas agrícolas do Pantanal com cultura de arroz irrigado, que segundo o Semac (2010) coloca o município como grande produtor de Arroz do estado de MS, produzindo em 2010um total de 23.991 toneladas do grão com um rendimento de $5.763 \mathrm{~kg} / \mathrm{ha}$ (Figura 13).

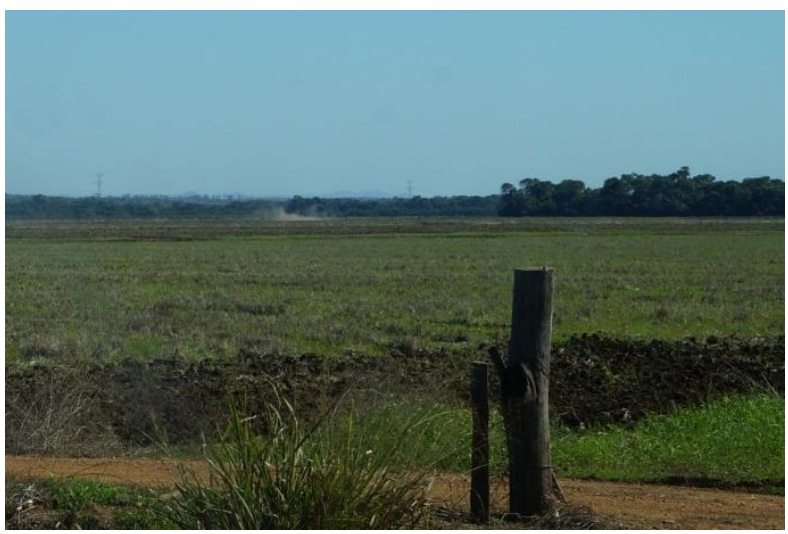

Figura 13. Arroz irrigado no período de preparação do solo.

\section{Conclusões}

A metodologia empregada a partir das geotecnologias no mapeamento do uso e cobertura da terra possibilitou a compreensão de sua dinâmica espaço-temporal no município de Miranda-MS. A aplicação das técnicas de Correção Atmosférica e NDVI auxiliaram no processo de construção dos mapas apresentados, uma vez que contribuíram para amenizar as diferenças oriundas de processos físicos estabelecidos na área de estudo durante o imageamento com impacto nas imagens (dinâmica atmosférica de períodos com acentuadas diferenças climáticas - período seco normal e a excepcionalidade climática do ano de 2011), distinguindo os diferentes tipos de uso e cobertura da terra.

Evidencia-se a partir das análises apresentadas a consolidação da pecuária extensiva na região, uma vez que o relevo plano do Pantanal e adjacências não oferece nenhum impedimento à ocupação antrópica, especificamente à mecanização e consequente implantação de pastagens.

Na porção sudoeste do município, áreas da Serra da Bodoquena, pela conformação geomorfológica, com declives acentuados, tem dificultado a utilização destas áreas ao impedir a mecanização. Ainda, devido a sazonalidade das cheias no Pantanal, estas áreas também preservam grande parte da vegetação, garantindo desta maneira a preservação de fragmentos importantes do Cerrado.

\section{Agradecimentos}

Os autores agradecem ao apoio científico do Programa de Pós-Graduação em Geografia Mestrado, da Universidade Federal de Mato Grosso do Sul - Câmpus de Aquidauana (PPGEO UFMS/CPAQ) e ao auxílio financeiro da Coordenação de Aperfeiçoamento de Pessoal de Nível Superior (CAPES).

\section{Referências}

Ab'Saber, A.N., 2006. Brasil: paisagens de exceção : o litoral e o Pantanal Mato-Grossense: patrimônios básicos, 2. ed. Atelie Editorial, Cotia.

Almeida, R.V.J. de, Araújo, M. D. O. G., Silva, A.C., Senna, J.A. de, 2015. Comparação dos Métodos de Correção Atmosférica: "6S" e "DOS" processadas em dados do sensor TM/Landsat5 e correspondentes a região de ocorrência da turfeira. Simpósio Brasileiro de Sensoriamento Remoto [online] 17. Disponível: https://goo.gl/nvhKq2 Acesso: 20 out. 2017.

Alves, G.L., Centeno, C.V., Mianutti, J., Brito, S.H.A., 2012. Relações Sociais e pesquisa ambiental no Pantanal Sul-Mato-Grossense: quando o pesquisador precisa ser cidadão, in: Alves, G.L., Mercante, M.A., Favero, S., (Orgs.), Pantanal Sul-Mato-Grossense: ameaças e propostas. Autores Associados, São Paulo, pp. 05-28.

ANA. Agência Nacional das Águas, 2004. Implementação de Práticas de Gerenciamento Integrado de Bacia Hidrográfica para o Pantanal e Bacia do Alto Paraguai, in: Programa de Ações Estratégicas para o Gerenciamento Integrado do Pantanal e Bacia do Alto Paraguai: Relatório Final. Brasília. Disponível: https://goo.gl/SYE2tu Acesso: 27 nov. 2017.

Antunes, M.A.H., Freire, R.M.B., Botelho, A. S., Toniolli, L.H., 2003. Correções atmosféricas de imagens de satélites utilizando o modelo 6S. Congresso Brasileiro de Cartografia [online], 21. Disponível: https://goo.gl/GXtHGK Acesso: 08 nov. 2017.

Assine, M.L., Merino, E.R., Pupim, F.N., Warren, L.V., Guerreiro, R.L., Mcglue, M.M., 2016. Geology and Geomorphology of the Pantanal Basin, in: Bergier, I., Assine, M. L. (Orgs.), Dynamics of the Pantanal Wetland in South America. Springer, Springer, pp. 23-50. Disponível: https://goo.gl/Wf7aW4 Acesso: 24 abr. 2017. DOI 10.1007/978-3-319-18735-8

Bazzo, J.C., Freitas, D.A. F., Silva, M.L.N., Cardoso, E.L., Santos, S.A., 2012. Aspectos 
Revista Brasileira de Geografia Física v.11, n.04 (2018) 1458-1477.

geofísicos e ambientais do Pantanal da Nhecolândia. Revista de Geografia (UFPE) [online] 29. Disponível: https://goo.gl/rzRbYJ Acesso: 24 abr. 2017.

Bernardes, J.A., 2010. As estratégias do capital no complexo da soja, in: Castro, I.E. de, Gomes, P. C. C., Correa, R.L. (Orgs.), Brasil: questões atuais da reorganização do território. Bertrand Brasil, Rio de Janeiro, pp. 325-366.

Brito, D.S., Leite, E.F., 2015. Aplicação da metodologia do DFC para avaliar o potencial erosivo natural da bacia hidrográfica do Rio Água Suja, Tocantins (Brasil). Revista Brasileira de Geografia Física [online] 8. Disponível:

https://periodicos.ufpe.br/revistas/rbgfe/article/ view/233459/27155 Acesso: 05 abr. 2018.

Câmara, G., Medeiros, J.S., 1998a. Princípios Básicos de Geoprocessamento, in: Assad, E.D., Sano, E.I. (Orgs.), Sistemas de Informações Geográficas: Aplicações na Agricultura. Embrapa, Brasília, pp. 03-10.

Câmara, G., Medeiros, J.S., 1998b. Operações de análise geográfica, in: Assad, E.D., Sano, E.I. (Orgs.), Sistemas de Informações Geográficas: Aplicações na Agricultura. Embrapa, Brasília, pp. 67-91.

Câmara, G., Monteiro, A.M., Fucks, S.D., Carvalho, M.S., 2004. Análise Espacial e Geoprocessamento, in: Druck, S., Carvalho, M.S., Câmara, G., Monteiro, A.V.M. (Eds.), Análise Espacial de Dados Geográficos, EMBRAPA, Brasília, p. 1-26. Disponível: https://goo.gl/T58iHM Acesso: 24 abr. 2017.

Câmara, G., Souza, R.C. M., Freitas, U.M., Garrido, J., 1996. Spring: Integrating remote sensing and GIS by object-oriented data modelling. Computers\&graphics [online] 20. Disponível: https://goo.gl/YUuC8n Acesso: 24 abr. 2017.

Câmara, G., Souza, R.C.M., Freitas, U.M., Paiva, J.A., 1993. Spring: Concepção, Evolução, Perspectivas. Simpósio Brasileiro de Sensoriamento Remoto [online] 7. Disponível: https://goo.gl/HXxjWR Acesso: 24 abr. 2017.

Carvalho Junior, W., Chagas, C. da S., Bhering, S.B., Silva, E.F. da, Amaral, F.C.S. do., Pereira N.R., Gonçalves, A.O., Zaroni, M.J., Áglio, M.L.D., Amorim, A.M., Lopes, C.H.L., Earp, C.G. de S., Pinheiro, T.D., Fernandes, T.G., Rodrigues, R.S., 2009. Zoneamento Agroecológico do município de Miranda-MS. Boletim de Pesquisa e Desenvolvimento [online] 140. Disponível: https://goo.gl/D7He4i Acesso: 29 nov. 2017.
CONAB. Companhia Nacional de Abastecimento, 2013. Perspectivas para a agropecuária, Brasília.

CPRM. Companhia de Pesquisa de Recursos Minerais, 2006. Mapa Geológico do Estado de Mato Grosso do Sul. Campo Grande. Disponível: http://geosgb.cprm.gov.br/ Acesso: 28 nov. 2017.

Crispim, S.M.A. Abreu, U.G.P., Pellegrin, L.A., 2013. Área desmatada no município de Miranda, MS no período de 1994 a 2007. Simpósio Sobre Recursos Naturais e Socioeconômicos do Pantanal [online] 6. Disponível: https://goo.gl/RkTUWX Acesso: 28 nov. 2017.

Silva, S.R.R., Chaves, I. B., Alves, J.J.A., 2010. Sensoriamento remoto e geoprocessamento aplicados ao zoneamento geoambiental: Bacia Hidrográfica do Açude Camará-PB. Mercator [online] 09. Disponível: https://goo.gl/5PBzTs Acesso: 24 abr. 2017. 10.4215/RM2010.0920. 0015

Facco, D.S., Benedetti, A.C., Kaiser, E.A., Pereira Filho, W., 2017. Avaliação da dinâmica do uso e cobertura da terra no município de Faxinal do Soturno no Estado do Rio Grande do Sul, in: Perez Filho, A. Amorim, R. R. (Org.), Os Desafios da Geografia Física na Fronteira do Conhecimento, UNICAMP, Campinas, p. 68466855. Disponível: https://goo.gl/9MimDU Acesso: 05 abr. 2018.

Ferrari, D.L., Silva, J.,Abdon, M. de M., 2009. Avaliação do uso de NDVI em imagens CBERS-2B/CCD na caracterização de pastagens degradadas no município de Camapuã, MS. Simpósio de Geotecnologias no Pantanal [online] 2. Disponível: https://goo.gl/j6XrA4 Acesso: 24 abr. 2017.

Ferraz, R.G.B., 2006. Antropização da Bacia Hidrográfica do Rio Miranda: Alterações Climáticas, Recursos Naturais e Desenvolvimento. Dissertação (Mestrado). Campo Grande, UCDB. Disponível: https://goo.gl/acnK2D Acesso: 24 abr. 2017.

Fitz, P.R., 2008. Geoprocessamento sem complicação. Oficina de Textos, São Paulo.

Florenzano, T.G., 2011. Iniciação em sensoriamento remoto. Oficina de Textos, São Paulo.

França, L.C.J., Lisboa, G. dos S., Silva, J.B.L., Cerqueira, C.L., Stepka, T.F., 2017. Uso e cobertura da terra para o município de Clevelândia, Paraná, Brasil. Agrarian[online] 10 . Disponível: <http://ojs.ufgd.edu.br/index.php/agrarian/articl e/view/6728/4161> Acesso: 05 abr. 2018. https://doi.org/10.30612/agrarian.v10i38.6728 
Revista Brasileira de Geografia Física v.11, n.04 (2018) 1458-1477.

Francisco, P.R.M., Pereira, F.C., Brandão, Z.N., 2015. Mapeamento da Aptidão Edáfica para Fruticultura Segundo o Zoneamento Agropecuário do Estado da Paraíba. Revista Brasileira de Geografia Física [online] 08. Disponível: https://goo.gl/fsHv6w Acesso: 08 nov. 2017.

Galdino, S., Silva, J.S.V., 2006. Análise da inundação de agosto de 1998 à jusante da cidade de Miranda, MS, no Pantanal. Simpósio de Geotecnologias no Pantanal [online] 1. Disponível: https://goo.gl/gsCKnY Acesso: 28 Nov. 2017.

Gavlak, A.A., Prado, B.R., Barros, M.A., 2013. Padrões de ocupação no Pantanal brasileiro e sua dinâmica entre os anos de 2002 e 2008: sensoriamento remoto e mineração de dados espaciais aplicados à análise espaço temporal do desmatamento. Simpósio Brasileiro de Sensoriamento Remoto [online] 16. Disponível: http://marte2.sid.inpe.br/col/dpi.inpe.br/marte2/ 2013/05.29.00.11.58/doc/p0946.pdf Acesso: 24 abr. 2017.

Gazolla, B.L.; Gonçalves, F.V., 2017. Caracterização do Processo de Erosão das Margens do Rio Miranda na Região do Passo do Lontra, Corumbá, Mato Grosso do Sul. Anuário do Instituto de Geociências - UFRJ [online] 40. Disponível:

http://ppegeo.igc.usp.br/index.php/anigeo/articl e/view/11496/10952 Acesso: 05 abr. 2018. http://dx.doi.org/10.11137/2017_2_144_152

Gonçalves, A.O., Pereira, N.R., Costa, L.L., 2006. Caracterização climática e aptidão das culturas anuais e perenes no zoneamento pedoclimático do estado do Mato Grosso do Sul - $1^{\mathrm{a}}$ fase. Embrapa Solos [online] 99. Disponível: https://goo.gl/f1UjxL Acesso: 29 nov. 2017.

Harris, M., Tomas, W., Mourão, G., Silva, C., Guimarães, E., Sonoda, F., Fachim, E., 2005. Desafios para proteger o Pantanal brasileiro: ameaças e iniciativas em conservação. Megadiversidade [online] 01. Disponível: https://goo.gl/ufPQTx Acesso: 24 abr. 2017.

Hogan, D.J., Marandola Jr., Ojima, R., 2010. População e ambiente: desafios à sustentabilidade. Blücher, São Paulo.

IBGE. Instituto Brasileiro de Geografia e Estatística, 2017a. Produção Agrícola Municipal 2016. Rio de Janeiro. Disponível:https://goo.gl/YQ9fa2 Acesso: 28 nov. 2017.

IBGE. Instituto Brasileiro de Geografia e Estatística, 2010. Censo Demográfico 2010. Rio de Janeiro. Disponível: https://goo.gl/F7N2Li Acesso: 28 nov. 2017.
IBGE. Instituto Brasileiro de Geografia e Estatística, 2013. Manual técnico de uso da terra. Rio de Janeiro. Disponível: https://goo.gl/cU7n96 Acesso: 01 nov. 2017.

IBGE. Instituto Brasileiro de Geografia e Estatística, 2017b. Produção da Pecuária Municipal 2016. Rio de Janeiro. Disponível: https://goo.gl/BiSvRq Acesso: 28 Nov. 2017.

IBGE. Instituto Brasileiro de Geografia e Estatística. 2017. Cadastro Central de Empresas 2014. Rio de Janeiro. Disponível:Acesso: 24 abr. 2017.

CPTEC. Centro de Previsão do Tempo e Estudos Climáticos, 2006. Boletim de informações climáticas. Brasília. Disponível: https://goo.gl/74SZNU Acesso: 01 nov. 2017.

INPE. Instituto Nacional de Pesquisas Espaciais, 2017. Objetivos do projeto SPRING. Sistema de Processamento de Informações Geográficas. São José dos Campos. Disponível: https://goo.gl/RXIHX. Acesso: 01 nov. 2017.

Landau, E.C., Guimarães, D.P., 2011. Análise Comparativa entre os modelos digitais de elevação ASTER, SRTM e TOPODATA. Simpósio Brasileiro de Sensoriamento Remoto [online] 15. Disponível: https://goo.gl/766wLP Acesso: 24 abr. 2017.

Leite, E.F., Rosa, R., 2012. Mapeamento Geomorfológico: A Carta de Energia do Relevo da Bacia Hidrográfica do Rio Formiga-TO. Revista Brasileira de Geografia Física [online] 05. Disponível: https://goo.gl/SzXr1f. Acesso: 01 nov. 2017.

Leite, V.A.W. Leite, E.F., 2016. Suscetibilidade à erosão laminar no município de Miranda/MS. Simpósio de Geotecnologias no Pantanal, [online] 6. Disponível: https://goo.gl/TCyAEu. Acesso: 03 fev. 2017.

Loureiro, C.V., 2011. A vulnerabilidade como indicador de qualidade ambiental em área do baixo curso dos rio Maranguapinho e Ceará/CE: Subsidio para o planejamento ambiental. Dissertação (Mestrado). Fortaleza, Universidade Federal do Ceará. Disponível: https://goo.gl/koJXK1 Acesso: 24 abr. 2017.

Maranhão, D.D.C., Pereira, M.G., Costa, E.M., Anjos, L.H.C. dos., 2017. Correção de Imagens e caracterização do uso da terra no município de Pinheiral, Estado do Rio de Janeiro, Brasil. Caminhos de Geografia [online] 18. Disponível: http://www.seer.ufu.br/index.php/caminhosdeg eografia/article/view/36893/20587 Acesso: 05 abr. 2018. http://dx.doi.org/10.14393/RCG186214

Matiello, S., Cerri, F., Pagani, C.P., Lima, J.S., 2017. O uso do geoprocessamento para 
Revista Brasileira de Geografia Física v.11, n.04 (2018) 1458-1477.

delimitação e análise das Áreas de Preservação abr.

2018.

$10.1590 / \mathrm{S} 1413$

Permanente de um córrego em Nova Mutum

Paraná-RO. Revista

Presença

Geográfica[online] $06 . \quad$ Disponível: https://goo.gl/K5hPS8 Acesso: 05 abr. 2018.

Mato Grosso do Sul, Governo do Estado do., 1990. Atlas Multirreferencial do Estado de Mato Grosso do Sul. Secretaria de Planejamento e Coordenação Geral, Campo Grande.

Mato Grosso do Sul, Governo do Estado do., 2011. Caderno Geoambiental das Regiões de Planejamento do MS. SEMAC, Campo Grande. Disponível: https://goo.gl/YBhNif Acesso: Acesso: 27 nov. 2017.

Melo, O.A.G., Santos, M.L., 2010. Análise comparativa da Vulnerabilidade Ambiental Potencial ou Emergente da bacia hidrográfica do rio Baiano, Assis Chateaubriand/PR. Boletim Geográfico [online] 28. Disponível: http://goo.gl/eddWpF Acesso: 19 nov. 2015. 10.4025/bolgeogr.v28i2.10375.

Mendes, F. de S., Caridade, G.N.C., Pereira, G., Moraes, E.C., Arai, E., Rudorff, B.F.T., Mello, M.P., 2009. Análise do desmatamento no município de Miranda, MS no período de 1999 a 2009 utilizando classificação de imagens do modelo linear de mistura espectral. Simpósio de Geotecnologias no Pantanal [online] 2. Disponível: https://goo.gl/C2Rdea Acessado em: 22 nov. 2017.

Moreira, M.A., 2012. Fundamentos do Sensoriamento remoto e metodologias de aplicação. UFV, Viçosa.

Nascimento, V.E.S., Gass, S.L.B., Oliveira, L.J.C., 2017. Comparação dos índices de vegetação NDVI e SAVI na Floresta Nacional de Carajás. Salão Internacional de Ensino, Pesquisa e Extensão, [online] 9. Disponível: https://goo.gl/e957EE Acesso: 05 abr. 2018.

Novo, E.M.L. de M., 2010. Sensoriamento Remoto: Princípios e Aplicações. Blucher, São Paulo.

Padovani, C.R., Cruz, M., Padovani, S.L.A.G., 2004. Desmatamento do Pantanal brasileiro para o ano 2000. Simpósio Sobre Recursos Naturais e Socioeconômicos do Pantanal: Sustentabilidade regional [online] 4. Disponível em:https://goo.gl/LxyzdN Acesso: 05 abr. 2018.

Paranhos Filho, A.C., Moreira, E.S., Oliveira, A.K.M., Pagotto, T.C.S., Mioto, C.L., 2014 Análise da variação da cobertura do solo no Pantanal de 2003 a 2010 através de sensoriamento remoto. Engenharia Sanitária e Ambiental [online] Edição Especial. Disponível: https://goo.gl/FrFXid Acesso: 05

41522014019010000305.

PCBAP. Plano de Conservação da Bacia do Alto Paraguai, 1997. Plano de Conservação da Bacia do Alto Paraguai (Pantanal): Análise integrada e prognóstico da Bacia do Alto Paraguai. Brasília.

Ponzoni, F.J. Shimabukuro, Y.E., 2007. Sensoriamento Remoto no Estudo da Vegetação. Arêntese, São José dos Campos.

Resende, R.J.T.P., Alves, H.M.R., Alves, M.R., 2000. Utilização do SPRING para avaliação do uso da terra em agroecossistemas cafeeiros da região de Lavras-MG. Simpósio de Pesquisa dos Cafés do Brasil [online] 4. Disponível: https://goo.gl/WKi12c Acesso: 24 abr. 2017.

Rocha, C.H.B., 2000. Geoprocessamento: tecnologia transdisciplinar. Editora do Autor, Juiz de Fora.

Rodrigues, L.P. Leite, E.F., 2017. Dinâmica do uso e cobertura da terra na bacia hidrográfica do rio Aquidauana, MS, in: Peres Filho, A., Amorim, R. R. (Orgs.). Os desafios da Geografia Física na fronteira do conhecimento. [online] 01. UNICAMP, Campinas. pp. 6817- 6825. Disponível: https://goo.gl/kZf6Ns Acesso: 24 abr. 2017. https://doi.org/10.20396/sbgfa.v1i2017.1873

Rosa, E.P. da. Trentin, R., Dias, D.F., Santos, V.S. dos., 2017. Mapeamento do uso e ocupação da terra no município de Jaguari-RS, in: Perez Filho, A., Amorim, R. R. (Org.), Os Desafios da Geografia Física na Fronteira do Conhecimento. UNICAMP, Campinas, pp. 6890-6894. Disponível: https://goo.gl/nrsu2x Acesso: 05 abr. 2018.

Rosa, R., 2005. Geotecnologias na geografia aplicada. Revista do Departamento de Geografia [online] $16 . \quad$ Disponível: https://goo.gl/D5QUMm Acesso: 24 abr. 2017.

Rosa, R., Brito, J.L.S., 1996. Introdução ao geoprocessamento: sistema de informação geográfica. EDUFU, Uberlandia.

Sakamoto, A.Y., Bacani, V.M., Gradella, F.S. Desmatamento e alterações ambientais no Pantanal da Nhecolândia, MS, Brasil. Geonorte [online] 03. Disponível: https://goo.gl/bpU9de Acesso: 24 abr. 2017.

Santos, L.A.C., Batista, A.C., Neves, C.O.M.; Carvalho, E.V. de.; Santos, M.M.; Giongo, M., 2017. Análise multitemporal do uso e cobertura da terra em nove municípios do Sul do Tocantins, utilizando imagens Landsat. Agro@mbiente [online] 11. Disponível: https://revista.ufrr.br/agroambiente/article/view /3915/2264 Acesso: 05 abr. 2018. 
Revista Brasileira de Geografia Física v.11, n.04 (2018) 1458-1477.

http://dx.doi.org/10.18227/1982-

8470ragro.v11i2.3915

Santos, M., 1996. A natureza do espaço: técnica e tempo, razão e emoção. Hucitec, São Paulo.

SEMAC. Secretaria de Estado de Meio Ambiente, do Planejamento, da Ciência e Tecnologia, 2011. Diagnóstico socioeconômico de Mato Grosso do Sul, Campo Grande.

Silva, J. S.V., Abdon, M.M., Silva, M.P. da., Romero, H.R., 1998. Levantamento do desmatamento no Pantanal Brasileiro até 1990/91. Pesquisa Agropecuária Brasileira [online] $33 . \quad$ Disponível: https://seer.sct.embrapa.br/index.php/pab/articl e/view/5048. Acesso: 05 abr. 2018.

Silva, J. S.V., Abdon, M. M., Moraes, J.A., 2010. Desmatamento na bacia do Alto Paraguai no Brasil. Simpósio de Geotecnologias no Pantanal [online] 3. Disponível: https://goo.gl/cDFcqY Acesso: 24 Abr. 2017.

Silva, J.X., Veiga, T.C. Geoprocessamento Aplicado à Identificação de áreas potenciais para atividades turísticas: o caso do município de Macaé-RJ, in: Silva, J.X. da., Zaidan, R.T. Geoprocessamento \& análise ambiental: aplicações. Bertrand Brasil, Rio de Janeiro, pp. 179-215.

Soares, A.F. 2001. Sistema de informações geográficas - SIG/SPRING para modelagem e espacialização de dados de fertilidade do solo. Disponível: https://goo.gl/pf9oiG Acesso: 24 abr. 2017.

Soares, A.F., 2001a. Utilização de Interpoladores na Geração de Grades do Spring para Elaboração de Modelos Numéricos de Terreno Utilizando Dados de Fertilidade do Solo. Disponível: https://goo.gl/DFWPUy Acesso: 24 abr. 2017.

USGS. United States Geological Survey, 2017a. What are the band designations for the Landsat satellites? Disponível: https://goo.gl/fGCVCM Acesso: 29 nov. 2017.

USGS. United States Geological Survey, 2017b. Landsat8. Disponível: https://goo.gl/odnBhz Acesso: 29 nov. 2017.

USGS. United States Geological Survey, 2017d. TechnicalDetails. Disponível: https://goo.gl/MEyXza Acesso: 29 nov. 2017.

USGS. United States Geological Survey., 2017c. Landsat5 History. Disponível: https://goo.gl/DFWPUy Acesso: 29 nov. 2017.

Valeriano, M. de M., 2008. Dados topográficos, in: Florenzano, T. G. (Org.), Geomorfologia: conceitos e tecnologias atuais. Oficina de Textos, São Paulo, pp. 72-104.
Valeriano, M. de M., 2008a. TOPODATA: Guia para utilização de dados geomorfológicos locais. INPE, São José dos Campos. Disponível: https://goo.gl/G8Mosc Acesso: 24 abr. 2017.

Verona, J.A., Galina, M.H., Troppmair, H., 2003. Geografia e Questões Ambientais. Revista de Geografia da UFC [online] 04. Disponível: https://goo.gl/gVT8fi Acesso: 19 nov. 2015.

WWF-BRASIL. World Wildlife Fund Brasil, 2009. Bacia do Alto Paraguai Cobertura Vegetal: Monitoramento das alterações da cobertura vegetal e uso do solo na Bacia do Alto Paraguai Porção Brasileira: Período de Análise: 2002 a 2008. Brasília, DF. Disponível: https://goo.gl/7QUGxi Acesso: 24 nov. 2017.

WWF-BRASIL. World Wildlife Fund Brasil, 2013. Bacia do Alto Paraguai Cobertura Vegetal: Monitoramento das alterações da cobertura vegetal e uso do solo na Bacia do Alto Paraguai Porção Brasileira: Período de Análise: 2010 a 2012. Brasília. Disponível: https://goo.gl/qFMXJ5 Acesso: 24 nov. 2017.

WWF-BRASIL. World Wildlife Fund Brasil, 2015. Bacia do Alto Paraguai Cobertura Vegetal: Monitoramento das alterações da cobertura vegetal e uso do solo na Bacia do Alto Paraguai Porção Brasileira: Período de Análise: 2012 a 2014. Brasília. Disponível: https://goo.gl/7sVrqw Acesso: 24 nov. 2017.

Zaidan, R.T., 2017. Geoprocessamento Conceitos e Definições. Revista de Geografia. Revista de Geografia [online] $07 . \quad$ Disponível: https:/geografia.ufjf.emnuvens.com.br/geograf ia/article/view/206/170 Acesso: 05 abr. 2018. 